Revista lus et Praxis, Año 26, № 2, 2020, pp. 193 - 218

ISSN 0717 - 2877

Universidad de Talca - Facultad de Ciencias Jurídicas y Sociales

Discrecionalidad y potestades sancionadoras de la Administración

Rosa Fernanda Gómez González

Trabajo ingresado el 12 de junio de 2019 y aprobado el 30 de noviembre de 2019

\title{
Discrecionalidad y potestades sancionadoras de la Administración
}

\author{
DISCRETIONALITY AND SANCTIONING POWERS OF THE ADMINISTRATION
}

ROSA FERNANDA GÓMEZ GONZÁLEZ*

\begin{abstract}
RESUMEN
Este trabajo analiza la discrecionalidad en materia administrativa sancionadora, dando cuenta que la atribución de potestades discrecionales en el ejercicio de poderes sancionadores es una determinación deliberada y consciente del legislador en el marco del orden constitucional. La existencia de discrecionalidad en el ejercicio de poderes sancionadores permite a la Administración orientar su actividad represiva en orden a alcanzar los fines públicos que se le han encomendado, considerando las circunstancias específicas del caso, incluyendo su adecuación a ciertas opciones de política pública.
\end{abstract}

\section{ABSTRACT}

This paper analyzes the discretionality existing in terms of administrative sanctions, realizing that the attribution of discretionary powers in the exercise of sanctioning powers is a deliberate and conscious determination of the legislator within the framework of the constitutional order. In this way, the existence of discretion in the exercise of sanctioning powers allows the Administration to direct its repressive activity in order to achieve the public purposes entrusted to it, considering the specific circumstances of the case, including its adaptation to certain policy public options.

\section{PALABRAS CLAVE}

Sanciones administrativas, discrecionalidad, principio de legalidad, conceptos jurídicos indeterminados, margen de apreciación, criterios.

KEY WORDS

Administrative sanctions, discretion, principle of legality, indeterminate legal concepts, margin of appreciation, criteria.

\footnotetext{
* Profesora de Derecho Administrativo de la Pontificia Universidad Católica de Valparaíso, Valparaíso, Chile. Correo electrónico: rosa.gomez@pucv.cl. Esta investigación cuenta con el apoyo del Proyecto FONDECYT Postdoctoral № 3190494 "Sanciones administrativas y derechos fundamentales. Análisis de temas específicos a partir de los principios, garantías y derechos regulados en la Constitución" y del FONDECYT Regular № 359974 "Criterios y estándares para el control de la potestad sancionadora de la Administración: análisis de los mecanismos de revisión judicial y administrativa". Asimismo, cuenta con el apoyo del proyecto de investigación "Derecho Administrativo Sancionador 2.0" (2018-RTI-096688-B-100), Proyecto I+D+i «Retos Investigación» 2018, del Ministerio de Ciencia, Innovación y Universidades de España y del Fondo Europeo de Desarrollo Regional (FEDER). Orcid ID: 0000-00034769-6749.
} 


\section{Aspectos generales}

La discrecionalidad administrativa es uno de los temas de mayor complejidad en el Derecho administrativo $^{1}$, lo que se torna más problemático tratándose del ejercicio de potestades administrativas sancionadoras, al punto de que algunos rechazan la existencia de ámbitos de discrecionalidad en la aplicación de sanciones mientras que otros postulan su reducción ${ }^{2}$.

El carácter desfavorable de las sanciones, homologable a la pena penal ${ }^{3} y$, por lo tanto, a la estricta legalidad, en el sentido de que la ley debe regular todos y cada uno de los aspectos del ejercicio del poder punitivo, permiten explican, en alguna medida, esta resistencia o rechazo a la discrecionalidad. Asimismo, también contribuye a su supresión, la sinonimia que tradicionalmente se ha efectuado entre discrecionalidad y arbitrariedad, en circunstancias que solo un ejercicio abusivo de la primera dará lugar a la segunda ${ }^{4}$.

Otra razón se encuentra en la preeminencia de la ley. Los operadores jurídicos, y con justa razón, están convencidos de que solo la ley puede $y$, en cierta manera, debe anticipar las consecuencias jurídicas para la multiplicidad de supuestos de hechos a que puede dar lugar la realidad. En tal sentido, la notoria influencia que han desarrollado los principios de legalidad y de seguridad jurídica, han hecho que la supremacía de la ley haya sido un dogma casi absoluto, inmune a flaquezas y debilidades ${ }^{5}$, afirmación que en la actualidad se encuentra bastante atenuada. La superioridad o imperio de la ley, sustentada básicamente en su suficiencia y completitud, debe ser observada en términos relativos, bastando para ello, las siguientes consideraciones:

a) Las exigencias de abstracción y generalidad que debe reunir la ley ${ }^{6}$, dado que aun cuando el legislador puede y quiera regularlo absolutamente todo, la infinidad de supuestos de hecho a que puede dar origen la realidad hacen de dicha tarea casi una misión imposible.

\footnotetext{
${ }^{1}$ SOTO (2009), pp. 359-364. Por su parte, Cordero señala que una de las visiones que en Derecho administrativo existe respecto de la discrecionalidad la mantiene bajo "[...] una permanente sospecha, pues a través de su ejercicio es posible que el Estado actué de un modo contrario a los derechos de las personas, de manera que todo el sistema debe construirse para acotar y anular el ejercicio de dicha potestad", en CORDERO (2015), p. 83. En el Derecho comparado se puede ver discusión entre FERNÁNDEZ (1991) y PAREJO (1993).

${ }^{2}$ La jurisprudencia del Tribunal Supremo español considera que la actividad sancionadora de la Administración no es una actividad discrecional, sino una actividad típicamente jurídica o de aplicación de normas, lo cual permite un control total del supuesto de hecho que, en cada caso particular, es objeto de enjuiciamiento, control que por lo general se efectúa a través del principio de proporcionalidad, en SANTAMARÍA Y PAREJO (1992), p. 218.

${ }^{3}$ Desde la sentencia del Tribunal Constitucional, Rol № 244, la tesis clásica sostiene que las sanciones administrativas y las penas penales tendrían un común origen en el ius puniendi estatal, de allí que gran parte de la doctrina y la jurisprudencial de diverso orden hayan considerado a las sanciones como penas. En este sentido, la tesis más radical es sostenida hasta la actualidad por el profesor Eduardo Soto Kloss, para quien las "sanciones administrativas", son igualmente "penas", de acuerdo al artículo 20 del Código Penal nuestro (desde que al decir que no "se reputan" o "consideran" penas, el legislador ha reconocido explícita y formalmente que son penas), motivo por el cual le son aplicables las "garantías judiciales" que la Constitución ha previsto para los delitos, recientemente en SOTO (2014), pp. 3952. Lo anterior es sin perjuicio de la doctrina en la actualidad postula la autonomía del derecho administrativo sancionador (Román Cordero) y su construcción a partir de normas de Derecho Público (por ejemplo, Letelier y Cordero),

${ }^{4}$ No todo ejercicio de un poder discrecional dará lugar a la arbitrariedad, sino que solo su ejercicio abusivo e injustificado de ella puede originar aquella, en este sentido, cabe tener presente que todo acto administrativo es impugnable ante los tribunales inclusive aquellos dictados en atención a una potestad discrecional, por lo cual la motivación de este cumplirá un rol esencial. La Administración puede ejercer a gusto sus potestades discrecionales, pero debe tener presente que posteriormente deberá rendir cuentas de sus actos ante los tribunales, los cuales revisarán, en su caso, la legalidad o arbitrariedad de la decisión, en NIETO (2000), p. 360.

${ }^{5}$ NIETO (2000), pp. 26 y ss.

${ }^{6}$ Las leyes tienen que estatuir las bases esenciales de un ordenamiento jurídico, dejando a la potestad administrativa algún ámbito de indeterminación, por pequeño que sea. Si bien el legislador ha de ser claro y preciso en los preceptos generales que dicta, también lo es que, en el nivel siguiente, esto es, el administrativo, en donde recae la tarea de ejecutar los mandatos del legislador, en CEA (1984), p. 13.
} 
b) Luego, resulta una quimera sostener que la regulación legal posee tal nivel de perfección y claridad, de forma que la autoridad llamada a aplicarla solo le cabe un ejercicio de cognición (verificador de una realidad determinada) o de subsunción (relación lógica entre la norma y el hecho). Además, es preciso tener presente las complejidades propias del lenguaje utilizado por las normas, el cual, con sus características de vaguedad, ambigüedad y textura abierta contribuyen a generar zonas de incertidumbre, influyendo en el proceso interpretativo que deben llevar a cabo tanto funcionarios como jueces ${ }^{7}$.

c) Enseguida, cabe destacar que, aun en aquellas situaciones en las que se cuestiona la forma en que han sido conferidas potestades discrecionales para la aplicación de sanciones, los cambios efectuados a las normas respectivas dejan un ámbito de actuación y de decisión al órgano, como aconteció materia de valores y seguros ${ }^{8}$.

Sin cuestionar la importancia de la ley como fuente del Derecho y destacando la relevancia que tiene en el ámbito administrativo sancionador, toda vez que hay elementos de la potestad represiva que necesariamente deben estar establecidos a nivel legal, como la infracción y su sanción, cabe destacar que en este ámbito las potestades regladas no ejercen un predominio absoluto, sino que conforme al principio de legalidad es perfectamente posible que la norma contemple elementos tanto reglados como discrecionales.

De esta manera, la vigencia del principio de legalidad en materia sancionadora admite ciertos márgenes de discrecionalidad sujetos a los principios que dominan en un Estado de Derecho. La dinámica y compleja realidad que debe enfrentar la autoridad, junto a la necesidad de adoptar e implementar decisiones de política pública, justifican la existencia de un margen de acción que permita ejercer su poder represivo, ponderando las circunstancias y los fines de interés público que se deben alcanzar en cada caso en concreto.

Al efecto, cabe tener presente que nuestro país no dispone de una ley de bases sobre infracciones, sanciones y procedimiento administrativo sancionador y, no por ello, se pone en duda la legitimidad y plena operatividad de las sanciones administrativas. Además, en Chile solo desde 2003 existen una ley de base generales de los procedimientos administrativos, la cual ha sido aplicada como disposición supletoria en este ámbito ${ }^{9}$, no obstante, las sanciones han sido impuestas desde los albores de la república ${ }^{10}$.

En definitiva, en este trabajo demostraré que, sobre la base de evidencia normativa, jurisprudencial y científica, en materia de infracciones y sanciones administrativas, no existe un predominio absoluto y estricto de las potestades regladas, sino que junto a ellas concurren potestades de carácter discrecional. Además, se demostrará que la discrecionalidad ha sido deliberadamente atribuida por el legislador tratándose de potestades sancionadoras, por cuanto se estima necesaria para el ejercicio de dicha potestad.

\footnotetext{
${ }^{7}$ CASSAGNE (2016), pp. 236 y 238. En Chile ARÓSTICA (2016), pp. 15 y ss.

${ }^{8}$ Si bien la Ley № 21.000, de 2017, incorporó criterios para la determinación del rango y del monto específico de las sanciones de multas (artículo 38), dispuso en los numerales 2 de sus artículos 36 y 37 que la autoridad seleccionara algunas de las alternativas para establecer la forma de calcular las mismas, a saber, hasta: a) La suma de 15.000 unidades de fomento; b) El 30\% del valor de la emisión, registro contable u operación irregular o c) El doble de los beneficios obtenidos producto de la emisión, registro contable u operación irregular. ${ }^{9}$ QUEZADA (2017).

${ }^{10}$ GÓMEZ (2019).
} 


\section{Discrecionalidad administrativa en el ejercicio de poderes punitivos}

Se encuentra fuertemente arraigada la idea de que la potestad sancionadora de la Administración no puede admitir espacios de discrecionalidad, toda vez que se trataría de poderes que importan una significativa restricción a los derechos de los sujetos infractores. En otros términos, existe un rechazo generalizado, aun cuando se empleen conceptos jurídicos indeterminados valorativos ${ }^{11}$.

Con todo, paulatinamente la doctrina nacional ha venido reconociendo la existencia y la necesidad de discrecionalidad en el ámbito de las sanciones administrativas ${ }^{12}$, siendo una de sus principales preocupaciones no solo su atribución sino, fundamentalmente, la forma de su ejercicio y posterior control ${ }^{13}$.

La discusión respecto de la existencia de discrecionalidad en el orden sancionatorio no es nueva. En el Derecho español, García de Enterría y Fernández señalaron que hasta la Ley de la Jurisdicción contencioso-administrativa de 1956, los actos administrativos sancionatorios se calificaban como actos políticos o discrecionales y se excluían, por tanto, del control contencioso ${ }^{14}$. Por su parte, la jurisprudencia constitucional reconoció la posibilidad de que el legislador estableciera márgenes de discrecionalidad para imponer sanciones, aunque para ello era necesario grados de definición concretos ${ }^{15}$.

En la actualidad, la existencia o no de discrecionalidad administrativa en el ejercicio de potestades sancionadoras, se ha circunscrito a la oportunidad en el ejercicio de la potestad y a la etapa de determinación de la sanción concreta a imponer en cada caso ${ }^{16}$, aunque sin un consenso absoluto al respecto.

En cuanto a la oportunidad, se ha sostenido que aquella no necesariamente es una determinación reglada, ya que la autoridad puede no iniciar el procedimiento sancionador considerando diversos factores: la imposibilidad material, la falta de recursos económicos y humanos o la necesidad de dotar de eficacia una determinada regulación y mantener el buen

\footnotetext{
${ }^{11}$ BAÑO (2015), p. 468.

12 Para la doctrina "Evitar la discrecionalidad administrativa de una cohorte sancionatoria tiene sentido en el ámbito penal, pero no lo tiene en el ámbito administrativo", en LETELIER (2016).

${ }^{13}$ Uno de los primeros en tratar el tema en Chile fue Aróstica, quien señaló que en el contexto del proceso de descriminalización de ciertos delitos y su posterior conversión en infracciones administrativas, el legislador le encomendó a los órganos públicos potestades discrecionales para aplicar sanciones. Enseguida, señala que para cautelar los derechos de los terceros que puedan ser afectados a raíz del ejercicio arbitrario de potestades sancionadoras, existen dos mecanismos que limitan el actuar de la Administración: a) las pautas o indicios de razonabilidad de preconfiguradas por el legislador: y b) la prudencia impuesta por el juez, en ambos supuestos destaca la importancia del principio de proporcionalidad para limitar la discrecionalidad concedida a la Administración para establecer el quantum de la sanción (que para él sería la única instancia discrecional efectiva en la materia), en ARÓSTICA (1987), pp. 109-125. En un escrito posterior el autor señala que las sanciones forman parte de una pluralidad de poderes punitivos entregados a la discrecionalidad de la Administración, en ARÓSTICA (1991), pp. 173-195.

Años más tarde, el tema de la existencia de discrecionalidad en el ejercicio de la potestad sancionadora comenzaría a ser tratado en el ámbito sectorial, como un mecanismo necesario para racionalizar su aplicación y cumplimiento de los fines públicos del órgano, por ejemplo, en GUILOFF Y SOTO (2015), pp. 101-124; SOTO (2016), pp. 374-407, y HUEPE (2014), pp. 168-186.

${ }^{14}$ GARCÍA DE ENTERRÍA Y FERNÁNDEZ (2011), p. 173.

${ }^{15}$ Para el Tribunal Constitucional español es necesario en estos casos concretar la relación entre las infracciones y las sanciones. Así lo sostuvo a propósito de la aplicación del artículo 57 del antiguo Estatuto de los Trabajadores, en donde se indicó que el legislador podía dejar márgenes más o menos amplios a la discrecionalidad judicial y administrativa, pero en modo alguno podía quedar encomendada por entero a ella, véase STCE, Rol N²07/1990, de 17 de diciembre de 1990. Aunque, en otros casos se ha indicado que la configuración de una potestad discrecional sería inconstitucional por vulneración al principio de predeterminación de la sanción, si la ley no contempla criterios para su graduación, véase STCE, Rol № 14/1998, de 21 enero de 1998, fj. 10‥

${ }^{16}$ DESDENTADO (2010), pp. 341 y 342.
} 
funcionamiento de un sector en concreto ${ }^{17}$. Asimismo, hay ocasiones en que el ejercicio de la potestad sería desaconsejable, especialmente cuando se trata de infracciones de ínfima gravedad ${ }^{18}$. Esta noción busca determinar "cuándo" es realmente necesario castigar o persuadir ${ }^{19}$.

Por su parte, la doctrina que sostiene el carácter reglado u obligatorio de la potestad, lo ha argumentado en base a la unidad de ius puniendi, al principio de legalidad, de seguridad jurídica y en el interés general que se busca resguardar con su imposición ${ }^{20}$. No obstante, hay quienes, encontrándose en una tesis intermedia, proponen una síntesis de las dos posturas anteriores ${ }^{21}$.

En cuanto a la determinación de la sanción, también aparecen posiciones contrapuestas. Así, para algunos se trataría de un supuesto de discrecionalidad débil o instrumental, conforme a la cual la Administración posee un margen de apreciación de carácter eminentemente jurídico para aplicar un criterio o un concepto jurídico, aunque este sea indeterminado ${ }^{22}$. Para otros, la singularización de una sanción es una potestad esencialmente discrecional que comporta no solo una labor de concreción de elementos normativos, sino que también comprende la apreciación de las circunstancias de hecho y del sujeto que todavía no hayan sido valoradas en otras fases ${ }^{23}$. Así como también, hay quienes critican la constitucionalidad de las normas que permiten que la autoridad pueda graduar sanciones ${ }^{24}$.

Como queda de manifiesto, estos son los principales momentos en los cuales se ha planteado la discusión respecto de la discrecionalidad, con opiniones a favor o en contra de esta. No obstante, los ámbitos de discrecionalidad no se limitan solo a estas instancias. La presencia de la discrecionalidad se advierte en otros momentos del ejercicio de la potestad punitiva, tales como en la adopción de medidas alternativas a la misma o en la condonación de una sanción. Las explicaciones para ello son múltiples, pero, en síntesis, radican en la carácter abstracto y general de la ley - cuyo rol es eminentemente orientativo-, y en la circunstancia de que la autoridad administrativa no es un mero autómata aplicador de sanciones, sino que es una entidad destinada

\footnotetext{
${ }^{17}$ El principio de oportunidad es característico del ejercicio de la potestad sancionadora, pero, sin reconocer que se trata de un ámbito discrecional, indica que se trata de una alternativa o complemento a las técnicas positivas de fomento de la consecución de ese mismo interés general. Empero, el autor reconoce que el principio de oportunidad o la discrecionalidad en el ejercicio de la potestad sancionadora es una cuestión controvertida, con opiniones igualmente divididas, en CASINO (2015). En Chile, en VAN WEEZEL (2017), pp. 1015-1016.

${ }_{18}$ NIETO (2005), p. 133, para quien, "[...] la realidad se impone indefectiblemente y ella es la que nos enseña que es materialmente imposible sancionar y aun expedientar a todos los infractores. Sostener, por tanto, el carácter obligatorio supondría multiplicar por cien o por mil el número de funcionarios y ni aun asi". Por su parte, Huergo sostiene que configurar la iniciación del procedimiento sancionador como discrecional parece lo más razonable, dado que permite a la Administración "[...] economizar esfuerzos y concentrarse en los casos más importantes, realizando el verdadero fin de las normas sancionadoras, que no es sancionar, sino hacer que se cumpla la norma", en HUERGO (1995), p. 219.

19 GUILOFF Y SOTO (2015), p. 105.

20 GARCÍA DE ENTERRÍA Y FERNÁNDEZ (2011), pp. 198. Para quienes en modo alguno se puede admitir que abrir un expediente sancionatorio y sancionar dentro de él constituya una potestad discrecional. En este mismo sentido Lozano señala que la aceptación de la discrecionalidad de la acción sancionadora administrativa y la búsqueda de límites dentro de este reconocimiento no contribuye a la solución del problema de fondo, pues si las sanciones se aplicaran sin excepción en todos los supuestos previstos, no haría falta ese incremento desorbitado de la cuantía de las sanciones administrativas y, sobre todo, se lograría mucho mejor el fin de las sanciones, en LOZANO (2003), p. 89. En tanto, Desdentado precisa que el carácter reglado del ejercicio de la potestad y de la iniciación del expediente sancionador, no significa que la Administración tenga que perseguir todas las infracciones, puesto que se encuentra mermado por las limitaciones que impone la realidad y por la insuficiencia de los mecanismos de control de la inactividad administrativa, en DESDENTADO (2010), p. 342 y ss.

${ }^{21}$ REBOLLO (2015), p. 413.

22 DESDENTADO (2010), pp. 344 y ss.

${ }^{23}$ IZQUIERDO (2001), p. 252.

${ }^{24}$ En este sentido Casino señala que "[...] resulta compatible con la garantía del principio de legalidad sancionadora que el legislador atribuya discrecionalidad a la Administración dentro de unos límites para concretar el alcance o importe de la sanción", en CASINO (2015).
} 
al cumplimiento de diversos fines, para lo cual, la potestad punitiva se muestra como una más de las herramientas de que dispone para ello.

De esta manera, el planteamiento de una regulación totalmente reglada del ejercicio de la potestad sancionadora no es sostenible, no solo por la dificultad práctica que ello significaría para la actividad judicial, sino que también por los riesgos que el legalismo podría generar en el sistema represivo, principalmente, en lo que dice relación con la rigidez y falta de adaptabilidad a situaciones concretas. En definitiva, lo que se busca es trasladar el poder de decisión desde el legislador a la Administración, para que se adopten medidas dentro de los fines que comprende la programación legislativa. Es decir, se trata de establecer un proceso racional destinado a dar cumplimiento y eficacia a un cierto ámbito regulatorio.

En consecuencia, el establecimiento de márgenes de discrecionalidad en el ámbito administrativo sancionador constituye una manifiesta necesidad para el adecuado y correcto ejercicio de dicha potestad. De allí que el legislador va configurándola, mediante el uso de diversas técnicas, en ciertas instancias o momentos dentro de un procedimiento sancionatorio, como al inicio o en la etapa final del mismo.

Ahora bien, cabe reiterar que la existencia de discrecionalidad en este ámbito no la constituye en una "potestad arbitraria", como lo ha indicado en algunas ocasiones el Tribunal Constituciona $\left.\right|^{25}$, sino que, por el contrario, la configuración discrecional del poder represivo permite que la autoridad pueda ajustar el ejercicio del mismo a las particulares circunstancias que rodean la situación fáctica que debe resolver. En otras palabras, es precisamente la discrecionalidad la que permite al órgano administrativo ejercer razonablemente sus atribuciones sancionadoras.

\section{La necesidad de un cambio de paradigma}

Para Kuhn, un paradigma científico se conforma por un conjunto de conocimientos que una comunidad científica comparte ${ }^{26}$. No obstante, y tal como lo explica Nieto, tratándose de paradigmas jurídicos, es difícil que toda una generación participe de un mismo paradigma, por ello habla de un "paradigma dominante común" que se identifica con una época y momento histórico determinado, y que ha sido desarrollado a través de la progresión científico-jurídica por acumulación ${ }^{27}$.

Ahora bien, es perfectamente posible que un paradigma cambie, en la medida que los nuevos conocimientos científicos adquiridos indiquen que una "revolución" o "precisión" al paradigma es posible y, en algunos casos, necesaria ${ }^{28}$.

Bajo tal respecto, podemos señalar que, tratándose de potestades administrativas sancionadoras, el paradigma dominante común considera que su ejercicio debe ser estrictamente

\footnotetext{
${ }^{25}$ En la STC, Rol № 2.922-2015, de 29 de septiembre de 2016, el Tribunal señala que el precepto allí recurrido produce efectos contrarios a la Constitución, puesto que impone una potestad discrecional arbitraria que "[...] no se compadece con las exigencias mínimas de un Estado de Derecho, que permitan fundamentar la decisión y, luego de una detallada subsunción de los hechos al derecho, señalar de manera lógica y precisa cuál es la razón del quantum de la sanción, cumpliendo así con los presupuestos de un debido proceso administrativo;" (c. $\left.49^{\circ}\right)$.

${ }^{26} \mathrm{KUNH}$ (2015), p. 71.

${ }^{27}$ NIETO (2000), pp. 21 y ss.

${ }^{28}$ Para Kuhn una "revolución científica" se produce por anomalías o crisis que dan cabida a un reemplazo de un paradigma existente por otro, KUNH (2015), pp. 27 y 149.
} 
reglado ${ }^{29}$ y que, por tanto, no admite espacios a la discrecionalidad ${ }^{30}$. En otros términos, se ha magnificado el rol de los elementos reglados en este ámbito, sobredimensionado su extensión a todos los supuestos de ejercicio de la potestad represiva. Este paradigma se sostiene, además, por la homologación que se ha construido entre discrecionalidad y arbitrariedad, entendiendo que ambas son figuras perfectamente intercambiables ${ }^{31}$.

La hipótesis que aquí se plantea sostiene que contrariamente a lo que se estima, en el ejercicio de potestades sancionadoras existe discrecionalidad, la cual ha sido deliberadamente atribuida por el legislador a la autoridad respectiva. Además, que dicha discrecionalidad es necesaria para el ejercicio adecuado de la potestad sancionadora. Lo expuesto, no implica una apertura o habilitación a la ilegalidad, arbitrariedad, abuso o exceso, puesto que la atribución de discrecionalidad conlleva, como contrapartida, una serie de límites que equilibran su ejercicio y contribuyen a su control. En otras palabras, se trata de un cambio de paradigma en la forma de comprensión de los poderes sancionadores de la Administración desde las potestades regladas a la atribución de potestades discrecionales para su ejercicio.

La atribución de potestades sancionadoras, como se ha señalado se efectúa mediante una técnica legislativa que entrega un margen de actuación y decisión a la Administración, para que integre y complete la norma con los criterios necesarios para el ejercicio del poder represivo.

Este esquema se aprecia en la estructura normativa contenida en diversas disposiciones sancionatorias especiales, en las cuales se advierte que la habilitación de márgenes y ámbitos de decisión pueden operar desde el momento en que la autoridad toma conocimiento de la conducta constitutiva de infracción extendiéndose hasta el momento en que se adoptan las medidas para la ejecución de la sanción administrativa.

A continuación, se expondrán los principales argumentos que permiten justificar la existencia de discrecionalidad en el ámbito administrativo sancionador, dando cuenta, además, de la necesidad de estructurar esta potestad como una atribución fundamental para su adecuado ejercicio, subordinada a ciertos límites y mecanismos de control.

\footnotetext{
${ }^{29}$ Cea Egaña indicó que vulneraba los principios de reserva y de separación de los poderes la ley que atribuía "poderes discrecionalespunitivos" a los órganos públicos. Ahora bien, esta negativa tenía su origen fundamentalmente en el rechazo de potestades sancionadoras en manos de la Administración, las cuales, en aquella data se estimaba que debían ser de exclusiva competencia judicial, aun cuando se tratase de infracciones de bagatela, en CEA (1984), p. 16.

${ }^{30}$ Sánchez Morón critica aquellos casos en los cuales se ha sostenido que la cuantificación de las sanciones administrativas tiene siempre carácter reglado, incluso si la norma habilitante confiere a la Administración la facultad de determinar "discrecionalmente" la cuantía de las multas, para lo cual se utiliza la técnica de los conceptos jurídicos indeterminados. En aquellos casos "[...] el juez se apropia de la discrecionalidad que la norma ha concedido a la Administración", en SÁNCHEZ (1995), p. 22.

En Chile Cordero señala que "Si bien se ha sostenido tradicionalmente que las potestades sancionadoras son siempre regladas, la realidad nos demuestra que existe un margen de libre apreciación que queda entregado a la autoridad administrativa y en donde este principio [refiriéndose a la proporcionalidad] juega un importante rol al momento de interpretar dichas disposiciones e integrar algunos criterios en la determinación de la sanción", en CORDERO (2014), p. 256.

${ }^{31}$ En este sentido, cabe hacer presente que "arbitrio" y "arbitrariedad" son conceptos con distinto significado. El primero ha sido considerado como sinónimo de discrecionalidad, aunque ha sido específicamente vinculado con aquel margen de apreciación que tienen los jueces para decidir sobre las interpretaciones más correctas de las normas en relación con las controversias que debe resolver. En tanto, la arbitrariedad corresponde a un acto o proceder contrario a la justicia, la razón o las leyes dictado solo por voluntad o capricho de su autor, sin un razonamiento suficiente y sin explicación bastante de las razones en que se basa o careciendo estas de cualquier fundamento serio, véase MUÑOZ (2017), pp. 217 y 218. Es por lo que Nieto sostiene que arbitrio no es arbitrariedad, siendo el primero legítimo y el segundo inconstitucional, en NIETO (2000). Para mayor profundidad sobre este punto, se puede ver a FERNÁNDEZ (2016) y a MECCARELLI (1998), p. 40.
} 


\subsection{El carácter general y abstracto de la ley}

La ley es una norma abstracta por naturaleza, su vocación de generalidad le impide prever todas las posibles circunstancias concurrentes en un supuesto específico. Como consecuencia de ello, la atribución de potestades a la Administración contempla ámbitos o espacios para que aquella pueda concretar la programación contenida en la norma respectiva, a través de la integración de criterios o elementos que solo dicha autoridad, atendida su posición, puede efectuar.

En el ámbito sancionatorio, el legislador establece la potestad represiva como un mecanismo de reacción frente a la ocurrencia de ilícitos administrativos, a los cuales enlaza ciertas sanciones como consecuencia de los mismos. Ahora bien, atendida la generalidad y abstracción de la norma, el legislador ha optado por dotar a la autoridad sancionadora de poderes discrecionales, para que esta pueda resolver las situaciones concretas que puedan presentarse, vale decir, en los casos no decididos de antemano por la ley, le ha dado un margen para adoptar la alternativa más adecuada ${ }^{32}$. Este poder deberá ser concretado a través de elementos que permitan su efectiva imposición.

La potestad sancionadora, al igual que toda potestad pública, constituye un instrumento o herramienta atribuida con el propósito de que la autoridad pueda gestionar con ella, de la mejor forma posible, la satisfacción de los intereses generales, de manera que, la fijación normativa de sanciones de un modo absoluto o en términos estrictos supondría, en la mayoría de las veces, una conculcación de principios fundamentales como el de proporcionalidad ${ }^{33}$ y de aquellos los presupuestos propios del funcionamiento administrativo como lo son la eficacia, la eficiencia o la economía procedimental. En otras palabras, la rigidez de un esquema como este, ciertamente, entorpecería la labor de los órganos públicos en el cumplimiento de sus fines y, con ello a los particulares.

De esta manera, respecto de poderes sancionadores, no se trata de dar cumplimiento irrestricto al principio de legalidad a través de su configuración exhaustiva por medio de potestades regladas $^{34}$, sino que de habilitar a la autoridad de ciertos márgenes de acción para que pueda ejercer, conforme a los objetivos que persigue, de la manera más conveniente posible, la potestad sancionadora otorgada. En este ámbito los márgenes de decisión son bienvenidos por sobre las normas estrictas ${ }^{35}$.

Contrariamente a lo que se cree, la potestad sancionadora, como herramienta de gestión administrativa, precisa de un sistema normativo que permita adecuar su ejercicio a las circunstancias del caso concreto, las cuales son imposibles de prever a priori, integrando de manera debida y oportuna los elementos necesarios para equilibrar, por un lado, la finalidad que se busca con su ejercicio y, por el otro, las condiciones particulares del infractor y de la infracción. Es por lo

\footnotetext{
32 ARÓSTICA (1987), pp. 114 y ss. Este autor señala que “Por razones de orden práctico - ante la imposibilidad de la norma general y abstracta para prever todas las situaciones concretas que pueden presentarse- y precisamente para propender a la solución más justa y equitativa en cada caso singular, el legislador, la mayoría de las veces en el campo del Derecho administrativo sancionador, no ha vinculado a la autoridad con el imperativo categórico de tener que aplicar "la" medida, como sanción única e indivisible". Para el autor, los poderes discrecionales quedan reducidos en relación con el quantum de la sanción: el grado de rigor que repelerá la infracción, el objeto o contenido de la medida.

${ }^{33}$ IZQUIERDO (2001), p. 208.

${ }^{34}$ Sentencia de la Corte Suprema, Rol № 2.968-2010, de 25 de abril de 2012, en la cual se sostuvo que "[...] la naturaleza de las contravenciones administrativas [...] hace imposible su síntesis descriptiva en un precepto general como es una ley".

${ }^{35}$ LONDOÑO (2014), p. 160.
} 
que algunos autores han sostenido que la regla general en la materia es la habilitación de potestades discrecionales para el ejercicio de poderes sancionadores ${ }^{36}$.

Para la doctrina nacional el "mandato legislativo" basado en la legitimidad democrática de la ley y en la certeza y seguridad jurídica que aquella proporciona, resulta imposible de aplicar, por cuanto la realidad supera la previsibilidad de la norma. Los avances tecnológicos, la evolución de los mercados, los movimientos sociales, la inserción en un mundo cada vez más globalizado, las nuevas formas organizativas de negocios, entre otros, hacen que la ley no logre regularlo todo o que, una vez que cree haberlo hecho, la realidad ha cambiado nuevamente ${ }^{37}$.

\subsection{La habilitación legislativa de márgenes de decisión administrativa}

La tendencia actual permite sostener que el legislador no concibe el funcionamiento de los órganos administrativos sin potestades sancionadoras ${ }^{38}$, toda vez que las considera necesarias para la satisfacción de sus objetivos ${ }^{39}$. Así, es habitual que las leyes destinen algunos artículos a regular infracciones y sanciones, o bien, que leyes vigentes, sean modificadas para ajustar el ejercicio de la potestad o incrementar su intensidad ${ }^{40}$.

Para configurar una potestad sancionadora el legislador recurre a una técnica normativa mixta, constituida por un binomio de potestades regladas y discrecionales, las cuales operarán de manera concatenada y colaborativa durante su ejercicio. Cada una estará conformada bajo diversos énfasis, los cuales dependerán del nivel de densidad normativa atribuida a cada una de ellas, atendidos los fines y objetivos que se buscan lograr con su establecimiento ${ }^{41}$.

En primer lugar, existen elementos reglados cuya consideración es esencial. Así, para que una autoridad ejerza su poder punitivo, la ley debe regular su núcleo esencial, conforme al cual la atribución debe estar establecida en una norma de rango legal (reserva legal) y, además, la conducta infraccional y la sanción junto con su extensión deben estar dispuestas previamente en una ley

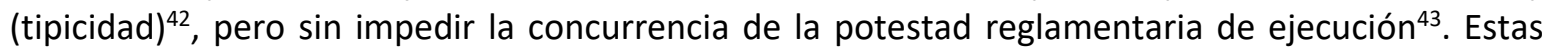
exigencias regladas mínimas de predeterminación normativa también han sido sostenidas por Contraloría General de la República, la cual ha señalado que toda potestad, como lo es la

\footnotetext{
${ }^{36}$ Aróstica señala que, salvo excepciones, “[...] la norma habilitante ha renunciado a particularizar anticipadamente, como forma de conducta única, aquella sanción proporcionada al caso real”, en ARÓsTICA (1987), p. 114.

${ }^{37}$ Se debe recurrir a la utilización de términos amplios y generales ( $v$.gr. utilidad pública, interés general, buena fe, orden público, etc.), comprendidos bajo la expresión de "conceptos jurídicos indeterminados", o a potestades discrecionales, para que la Administración determine algunos aspectos, como la oportunidad para actuar, el cómo hacerlo y el qué decidir a este respecto, en CORDERO (2014), p. 186. No obstante, el mismo autor lamenta la mínima vinculación legal que se produce en algunos casos, dejando un amplio margen a la discrecionalidad administrativa, CORDERO (2014), p. 191.

${ }^{38}$ AGUERREA (2005), p. 51.

${ }^{39}$ CURY (2005), p. 109. Sobre este punto RODRÍGUEZ (1987), pp. 120 y 130.

${ }^{40}$ Por ejemplo, las competencias en materia de infracciones y sanciones atribuidas a la autoridad sanitaria por la Ley № 21.020, de 2017, sobre tenencia responsable de mascotas y animales de compañía; la modificación introducida por la Ley № 21.000, de 2017, al sistema sancionatorio del mercado financiero o la reforma de la Ley № 21.064, de 2018 al Código de Aguas en materia de fiscalización.

${ }^{41}$ La determinación del carácter reglado o discrecional de la potestad sancionadora no debe ser abordada desde una perspectiva ontológica, sino que en atención a una calificación asociada a la densidad normativa que ha dado el legislador para el ejercicio de esa potestad, en FERRADA (2014), p. 247.

${ }^{42}$ STC, Rol № 480-2006, de 27 de julio de 2006.

${ }_{43}$ Para el Tribunal Constitucional chileno la legalidad en materia sancionatoria se cumple con la previsión de las infracciones y de las sanciones en la ley. Además, dicho principio no excluye la colaboración de la potestad reglamentaria de ejecución, salvo en aquellos casos en que la propia Constitución ha reservado a la ley y solo a ella disponer en todos sus detalles una determinada materia, en la STC, Rol № 480-2006, de 27 de julio de 2006, c. 18 ‥
} 
sancionadora, debe ser atribuida por el legislador a la Administración ${ }^{44}$. En suma, tanto el poder sancionador como su ejercicio son atribuciones reguladas por ley ${ }^{45}$.

Luego, esta "base reglada mínima" debe necesariamente complementarse con ciertas restricciones, generalmente de carácter constitucional, que le han sido impuestas al legislador para configurar potestades sancionadoras, a saber: a) le está proscrito establecer sanciones privativas de libertad por vía administrativa, incluyendo su sustitución por vía de apremio ${ }^{46}$; b) debe respetar la proporcionalidad entre la limitación del derecho fundamental y el objetivo constitucionalmente válido que se busca perseguir ${ }^{47}$; c) debe contemplar criterios para determinar el importe de la sanción específica a aplicar ${ }^{48}$; d) debe garantizar el derecho a un justo y racional proceso a través de un debido procedimiento administrativo ${ }^{49}$; e) toda sanción administrativa puede ser impugnada ante una instancia jurisdiccional, como garantía del derecho de acceso a la justicia ${ }^{50}$. A este listado, y producto del fallo SERNAC, cabe agregar la necesaria separación entre las funciones de fiscalización y sanción, en aquellos casos en los cuales no es posible garantizar los estándares de independencia e imparcialidad fijados por la jurisprudencia del Tribunal Constitucional chileno y por la Ley de Bases Generales de la Administración del Estado ${ }^{51}$.

Luego de ello, el legislador puede configurar normativamente los demás contornos del poder punitivo que entregará a la Administración, pudiendo optar por continuar regulando su ejercicio o por atribuir ámbitos específicos de actuación y de decisión al órgano respectivo.

Ahora bien, en las diversas leyes que contienen disposiciones sancionadoras, es habitual que el legislador otorgue a la Administración ciertos ámbitos de discrecionalidad para el ejercicio de la potestad represiva ${ }^{52}$. En este sentido, en la etapa final de un procedimiento sancionatorio es posible advertir con claridad los poderes discrecionales que tiene la Administración, dado que es allí donde la autoridad decide, con cierta autonomía, el tipo de sanción que aplicará y su intensidad, empero, existen otras instancias administrativas de carácter sancionador, en las cuales es dable apreciar dichos poderes.

En efecto, coexisten una serie de preceptos que contienen expresiones tales como: el procedimiento sancionatorio podrá iniciarse de oficio o a petición de parte ${ }^{53}$, constatada la infracción se podrán adoptar medidas provisionales ${ }^{54}$, la superintendencia podrá aplicar las

\footnotetext{
${ }^{44}$ Contraloría General de la República, dictamen № 71.670, de 14 de septiembre de 2014.

${ }^{45}$ NIETO (2012), p. 99.

${ }^{46}$ STC, Rol № 1.518-2009, de 21 de octubre de 2010.

${ }^{47}$ CORDERO (2014), p. 54. El Tribunal Constitucional español declaró inconstitucional un precepto que no establecía criterios para graduar las sanciones por infracciones a la legislación laboral, entregando su cálculo a una determinación singular o ad hoc de la autoridad, en la STCE, Rol N²07/1990, de 17 de diciembre de 1990.

48 Véase las sentencias de los casos cascadas, STC, Rol № 2.922-2015, de 29 de septiembre de 2016; Rol № 3.014-2016, de 14 de noviembre de 2017; Rol № 3.236-2016, de 24 de mayo de 2018; Rol № 3.542-2017, de 7 de mayo de 2018; Rol № 3.575-2017, de 7 de mayo de 2018 y Rol № 3.684-2017, de 7 de mayo de 2018.

${ }^{49}$ Véase STC, Rol № 376-2003, de 17 de junio de 2003 y Rol № 389-2003, de 28 de octubre de 2003, en las cuales, conociendo el Tribunal Constitucional del control preventivo de constitucionalidad de los proyectos de las leyes sobre transparencia, límite y control del gasto electoral y sobre la creación de la Unidad de Análisis Financiero, respectivamente, objetó la falta de un procedimiento administrativo sancionador para la aplicación de las sanciones por infracciones a sus preceptos, puesto que con dicha omisión se contravenía lo dispuesto en el artículo 19 № 3 de la Carta Fundamental.

${ }^{50}$ Aquí se comprenden los fallos recaídos en materia de solve et repete. Recientemente la STC, Rol № 3.487-2017, de 5 de marzo de 2019, a propósito de la consignación previa reclamación judicial establecida en el artículo 19 inciso 2o de la Ley № 18.410, de 1985.

${ }^{51}$ STC, Rol N 4.012-2017, de 18 de enero de 2018, c. 38ㅇ. Asimismo, véase el voto del ministro Romero, cc. 16ㅇ a 18ㅇ․

52 Para Londoño se trata de una normativa inspirada en ideales consecuencialistas, con márgenes de flexibilidad o discrecionalidad aplicativa, LONDOÑO (2014), pp. 165 y 166.

${ }^{53}$ Artículo 27 del DL № 3.538, de 1980.

${ }^{54}$ Por ejemplo, los artículos 14 bis y 15 de la Ley № 18.755, de 1989 y 3 letras g) y h) y 48 de la Ley № 20.417, de 2010.
} 
sanciones que estime pertinentes ${ }^{55}$, la autoridad podrá fijar el monto de la multa a su elección ${ }^{56}$, al resolver el recurso la autoridad podrá confirmar las sanciones impuestas, modificarlas, dejarlas sin efecto o imponer otras distintas ${ }^{57}$, en casos calificados se podrá, a petición de los infractores, pactar plazos para el pago de las multas que se les hayan impuesto ${ }^{58}$, se podrán decomisar los elementos o insumos que hubieren servido para cometer la infracción y los productos resultantes de ella ${ }^{59}$, entre otros. En otros casos, se atribuye expresamente o mediante el uso de fórmulas que atribuyen un margen de decisión a la autoridad, v. gr. artículo 162, inciso 3ㅇ del Código Tributario ${ }^{60}$, el que establece que

Si la infracción pudiere ser sancionada con multa y pena privativa de libertad, el Director podrá, discrecionalmente, interponer la respectiva denuncia o querella o enviar los antecedentes al Director Regional para que persiga la aplicación de la multa que correspondiere a través del procedimiento administrativo previsto en el artículo anterior.

O el artículo 11 inciso final de la Ley № 18.902, que crea la Superintendencia de Servicios Sanitarios, el que señala que "El monto de la multa será determinado prudencialmente en consideración a la cantidad de usuarios afectados y la gravedad de la infracción". Tales enunciados no son más que manifestaciones de la señalada discrecionalidad.

Las explicaciones a este fenómeno pueden ser múltiples, pero en la mayoría de los casos responden a las características de generalidad y abstracción que debe reunir la ley, consecuencia de lo cual no corresponde desarrollar una regulación sancionatoria acabada, exhaustiva y pormenorizada de las formas en que deberá ser ejercida esta potestad por la autoridad ante la multiplicidad de supuestos fácticos que pueden darse en la realidad, frente a lo cual ha adoptado fórmulas normativas que entregan cierta discrecionalidad a la Administración ${ }^{61}$. Por ello, el principio de tipicidad en este ámbito es diverso al concebido para materias penales ${ }^{62}$. Además, con el objeto de alcanzar a todos los supuestos de hecho a que puede dar origen la realidad, el legislador ha optado por atribuir a la autoridad potestades discrecionales, evitando así dejar fuera situaciones que lo abstracto busca regular, pero que, en concreto, serían complejas de describir hasta en sus más mínimos aspectos.

Tratándose de potestades sancionatorias, el legislador puede atribuir dicha potestad otorgando ámbitos de discrecionalidad o estableciendo conceptos jurídicos indeterminados ${ }^{63}$. En

\footnotetext{
${ }^{55}$ Artículo 28 inciso final del DL № 3.538, de 1980.

${ }^{56}$ Artículo 29 del DL № 3.538, de 1980.

${ }^{57}$ Artículo 16 de la Ley № 18.755 de 1989.

${ }^{58}$ Artículo 23 de la Ley № 18.755, de 1989.

${ }^{59}$ Artículo 24 de la Ley № 18.755, de 1989.

${ }^{60} \mathrm{Al}$ efecto, véase el dictamen № 14.000, de 2017.

${ }^{61}$ Para Gordillo "[...] es imposible en la práctica -e inconveniente- prever hasta el último detalle de lo que el órgano debe hacer: siempre quedará algún pequeño margen que deberá dejarse necesariamente al arbitrio del funcionario actuante", en GORDILLO (1974), pp. VIII, 26-27.

${ }^{62}$ En este sentido, en la sentencia de la Corte Suprema, Rol N 41.815-2016, de 1 de marzo de 2017, sobre reclamación de una sanción ambiental, se ha señalado: "Trigésimo cuarto: Que la naturaleza de las infracciones administrativas -y en especial en lo que guarda relación con los temas ambientales, donde confluyen componentes técnicos, dinámicos y sujetos a variabilidad en el tiempo- torna imposible su síntesis descriptiva dentro de un precepto general como lo es la ley, de suerte que el apotegma de tipicidad al traspasarse al campo sancionatorio de la Administración admite ciertos grados de atenuación".

${ }^{63}$ Sobre la atribución de conceptos jurídicos indeterminados a la Administración nuestros tribunales de justicia han señalado que "Que las cláusulas abiertas que incluye el legislador mediante fórmulas elásticas más o menos vagas -interés general, utilidad pública, bienestar general, salud pública - otorgan al administrador un flexible arbitrio interpretativo, pero en todas las situaciones, las causales que determinan la creación del acto deben ser razonables y acreditadas si el asunto se ventila en sede jurisdiccional", sentencia de la
} 
ambos casos la habilitación implica que la autoridad deberá completar e integrar el supuesto de hecho imperfecto ${ }^{64}$, mediante la incorporación de ciertos criterios o parámetros, aunque en el segundo de ellos su ámbito de acción será ciertamente más restringida, debiendo circunscribirse a los límites establecidos por el concepto ${ }^{65}$ y al carácter de los mismos ${ }^{66}$, determinando su concurrencia en términos disyuntivos.

Al respecto, se sigue la tesis que sostiene que existe discrecionalidad solo en el supuesto de hecho imperfecto de la norma jurídico-administrativa. De esta manera, se considera que no solo hay discrecionalidad cuando el legislador la configura directamente o mediante fórmulas que habilitan su ejercicio, sino que también hay discrecionalidad en los casos en que el legislador utiliza conceptos jurídicos indeterminados ( $v$ gr. de experiencia, prognosis, técnicos, entre otros) ${ }^{67}$, imponiendo a la autoridad el deber de precisar, dentro de un margen de apreciación, la zona de incertidumbre o vaguedad de los mismos ${ }^{68}$, por cuanto en dicho ámbito su aplicación exige una decisión del órgano, consistente en completar un requisito o elemento imperfecto del supuesto de hecho normativo ${ }^{69}$.

Corte de Apelaciones de Santiago, Rol № 3.029-1993 (c. $7^{\circ}$ ) y posteriormente confirmada por la sentencia de la Corte Suprema, Rol № 22.607-1994. En tanto, el Tribunal Constitucional chileno ha sostenido la necesidad de estos conceptos jurídicos indeterminados atendido que "[...] que buscan atrapar bajo ciertos estándares o fórmulas verbales, realidades variables", ello a propósito de la falta de especificidad que se le reprochada a la disposición del proyecto de ley televisión digital terrestre que establecía la "[...] obligación de transmitir campañas de utilidad o interés público", en STC, Rol № 2.541-2013, de 18 de noviembre de 2013, c. 50.

${ }^{64}$ La ausencia de previsión legislativa de un supuesto no es un indicativo de abstención de la actuación administrativa, sino que precisamente en estos casos la autoridad debe recurrir a parámetros para evaluar su corrección. Entender que la ausencia de una atribución explicita para un supuesto específico implicaría la inexistencia de potestades para intervenir en él lo que significaría que los fines establecidos en la norma no pudieran ser alcanzados, en GUILOFF Y SOTO (2015), pp. 116 y 177.

${ }^{65}$ Aróstica critica que la susceptibilidad con que los conceptos indeterminados pueden ser manipulados y utilizados para justificar cualquier decisión administrativa, eludiendo mayores fundamentaciones y haciéndola inasequible a toda revisión externa, contralora o judicial. Lo que preocupa mayormente al autor es que una norma constitucional o legal se respalde en dichos conceptos con el propósito de justificar una sanción o restricción de derechos por parte de la Administración, en ARÓSTICA (2016), pp. 25-26 y 32.

${ }^{66}$ Así, por ejemplo, si se trata de conceptos jurídicos indeterminados de carácter técnico habrá que estar a la forma en que han sido configurados en la norma, esto es, si operaran separada o juntamente con una determinación administrativa, además, en algunos casos, la concreción de su zona de certeza dependerá del sector regulado de que se trate.

${ }^{67}$ La definición de un concepto jurídico indeterminado en su zona de incertidumbre supone necesariamente adopción por parte de la Administración de un o más criterios de aplicación del concepto (que no están en la norma). Como señala Koch, la autoridad tendrá que adoptar criterios adicionales de decisión que completen (en sede aplicativa) el supuesto de hecho inacabado de la norma habilitante o bien un requisito imperfecto (por indeterminado en su zona de incertidumbre) del mismo. Según este autor, la única diferencia de tipo jurídico-metodológica que existe entre la perfección o integración del supuesto de hecho inacabado de una norma que habilita discrecionalidad y la que contempla un concepto jurídico indeterminado radica en el carácter acumulativo de la primera y el disyuntivo de la segunda. Así, en el primero caso si concurre A, B, C y D, opera la consecuencia jurídica Z; mientras que en el segundo si concurre $A$ o B, el concepto indeterminado se aplica, si concurre C y D este no se aplica, Véase KOCH (1979), p. 38 (en particular la nota 104, en la cual señala que "Demgegenüber stellen Ermessensermächtigungen eine Konjunktive Ergänzungsaufgabe; eine Ermessensbetätigung führt deshalb zur Einschränkung des Anwendungsbereichs einer Norm", esto es, que los poderes discrecionales constituyen una tarea complementaria conjuntiva y que una operación discrecional limita -u orienta- el alcance de una norma) y KOCH (1979), pp. 177 y ss. Sobre el particular, también véase a BACIGALUPO (1997), pp. 189-190.

En materia sancionadora, la tendencia en el derecho europeo de referencia pareciera tratar de configurar la potestad administrativa sancionadora como una potestad reglada, definiendo con la mayor precisión posible las conductas infractoras, las circunstancias que agravan o disminuyen la infracción y las sanciones aplicables en cada caso. Sin embargo, ello se flexibiliza con la utilización de "conceptos jurídicos indeterminados", los que son interpretados y aplicados por la Administración del Estado, pero que pueden ser revisados posteriormente por el tribunal competente. En este sentido, véase la Ley Orgánica 4/2015, de 2015, de protección de la seguridad ciudadana de España, la cual buscó recoger con un alto grado de detalle y precisión las conductas típicas y las sanciones aplicables a las mismas.

${ }^{68}$ Al efecto, $\mathrm{KOCH}$ (1979), pp. 34 y ss.

${ }^{69}$ En Alemania siguen esta teoría Walter Schmidt, Roland Geitmann, Gerd Schmidt-Eichstaedt, Klaus Obermayer, Hans Joachim Koch, Rüdiger Rubel y Karl Heinz Weber, todos en BACIGALUPO (1997), p. 185. En Francia con autores como, Bonnard, Eisenman y Rials, para los dos primeros es la indeterminación de la norma (lo que genera la potestad discrecional, mientras que para el último es la indeterminabilidad de la norma la que da origen a ella, en SUBRA DE BIEUSSESS (1994), p. 37. En España, la tesis es sostenida por BACIGALUPO (1997), p. 191, RODRÍGUEZ (2016), p. 150 y ss. y recientemente en DOMENECH (2019). 
Figura 1. Atribución directa de una potestad discrecional. Este tipo de atribución permite a la autoridad, mediante la acumulación de criterios, completar el supuesto de hecho imperfecto de la norma jurídico-administrativa. Luego de lo cual podrá determinar la consecuencia jurídica respectiva.

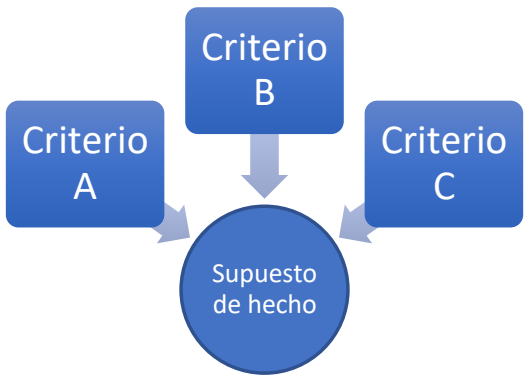

Figura 2. Establecimiento de conceptos jurídicos indeterminados (CII). Este tipo de atribución permite a la autoridad, mediante la reunión de criterios que operarán disyuntivamente, completar la zona de incertidumbre del concepto, con lo cual podrá establecer su aplicación negativa o positiva.

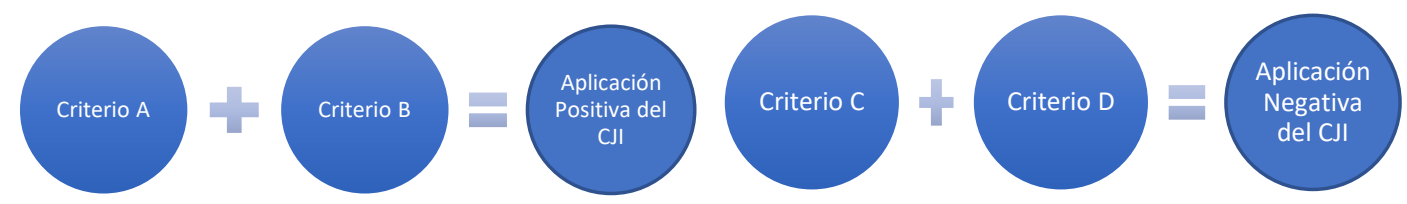

Mediante la integración de criterios, el operador jurídico perfecciona la norma, lo cual le permite discernir con certidumbre, o un mayor grado de ella, la consecuencia jurídica que corresponderá al caso particular respectivo ${ }^{70}$. Así, la gravedad de la infracción o la conducta reincidente del infractor, podrán llevar a la autoridad a determinar que la iniciación del procedimiento sancionador es imperativa. Por el contrario, la escasa gravedad del ilícito o el compromiso del infractor a reparar el daño causado, pueden incidir en el no ejercicio de la potestad punitiva.

En otras palabras, la integración de criterios o parámetros dirige la discrecionalidad en el ejercicio de potestades sancionadoras, la concurrencia y sinergia entre ellos permiten una adecuada ejecución de la actividad administrativa punitiva y una debida observancia a sus principios ${ }^{71}$. De esta

\footnotetext{
${ }^{70}$ Para algunos esta situación de intrínseco vacío es preocupante puesto que al habilitar y consentir que "[...] la Administración complete o integre la norma legal, puede dar pie a un abuso al momento de rematar la obra inconclusa del Legislador, con el consiguiente detrimento del derecho a una tutela judicial efectiva", y con ello propician la injusticia y la arbitrariedad, en ARÓsTICA (2016), p. 32.

${ }^{71}$ La fijación exacta de una sanción podría significar una vulneración al principio de proporcionalidad, puesto que no se podría adaptar la misma al supuesto de hecho concreto, en IZQUIERDO (2001), p. 219.
} 
manera la integración genera que la aplicación de una determinada consecuencia jurídica se transforme en una actividad reglada ${ }^{72}$.

Asimismo, cabe recordar que la Administración no tiene como objetivo principal de sus actividades la aplicación de sanciones, sino que busca la realización de ciertos fines públicos específicos $y$, en su caso, la protección de determinados bienes jurídicos colectivos o supraindividuales como la salubridad pública, el medio ambiente, el mercado financiero, la protección del consumidor, el recurso del recurso hídrico ${ }^{73}$. De esta manera, el poder punitivo es solo una de las otras tantas herramientas de que dispone la autoridad para cumplir con sus finalidades.

En definitiva, existe la intención legislativa en orden a otorgar a la Administración atribuciones de carácter discrecional (directamente o mediante conceptos indeterminados), a la Administración para el ejercicio de las potestades sancionadoras, cuya precisión en situaciones concretas le permite a la autoridad sincronizar, por una parte, los intereses generales que busca tutelar mediante la aplicación de sanciones y, por la otra, los objetivos particulares de castigo y prevención que dichas medidas conllevan como contrapartida ${ }^{74}$.

\subsection{La finalidad de la potestad administrativa sancionadora}

Otra contribución al paradigma actual respecto de la discrecionalidad está dada por la creencia de que las sanciones constituyen fines en sí mismos, en circunstancias que son un medio para alcanzar un fin o una herramienta para cumplir con la función administrativa ${ }^{75}$. La protección y tutela de los intereses públicos se encuentra precisamente en la amenaza que comporta su imposición en caso de que se cometa la conducta ilegal y no el contenido mismo de la sanción ${ }^{76}$. Así, para la autoridad ambiental es más importante la protección del medio ambiente que sancionar, de manera que aquella prefiere aceptar una autodenuncia y adoptar planes de cumplimiento antes que aplicar una sanción ${ }^{77}$.

Por ello, una sanción no necesariamente llegará a imponerse ${ }^{78}$. La autoridad puede considerar que es más adecuado para el cumplimiento de la finalidad respectiva la adopción de

\footnotetext{
72 La iniciación de un procedimiento sancionatorio podrá ser facultativa o no, empero una vez que concurran ciertos elementos, normalmente vinculados a la gravedad de la conducta, su incoación deviene en obligatoria, en CORDERO (2014), p. 301. Por el contrario, Bermúdez señala que en el "[...] ejercicio de potestades sancionadoras el legislador, normalmente, no entrega facultades de apreciación de la actuación, es decir, producida la infracción, ésta debe aplicar alguna de las sanciones previstas, dentro de las cuales sí existe un margen de apreciación, que se traduce en la discrecionalidad de elección", en BERMÚDEZ (2012), p. 7.

${ }^{73}$ Por ello, la Ley № 21.064, de 2018, introdujo modificaciones al Código de Aguas, en relación con el marco normativo que rige las aguas en materia de fiscalización y sanciones.

74 Esta "prevención" en el ámbito ambiental se ha denominado "disuasión". Al efecto, véase las Bases metodológicas para la determinación de sanciones ambientales de la SMA.

${ }^{75}$ Para Huego es una realidad que la Administración no puede castigar todas las infracciones, consecuencia de lo cual economiza esfuerzos y se concentra en los casos más importantes, realizando el verdadero fin de las normas sancionadoras, que no es sancionar, sino hacer que se cumpla la norma. La Administración debe ejercer la potestad sancionadora, e iniciar los procedimientos oportunos, no «a ciegas», sino teniendo en cuenta el fin para el que se le ha otorgado esa potestad, en HUERGO (1995), p. 219.

${ }^{76}$ HUERGO (2007), p. 229.

77 La Corte Suprema, sobre reclamación de una sanción ambiental, ha ratificado esta noción al señalar que tanto la Resolución de Calificación Ambiental y las condiciones por ella impuestas, como instrumentos destinados a la protección del medio ambiente, y “[...] se erige la sanción como un mecanismo tendiente a asegurar su cumplimiento y no como un fin en sí misma;", en sentencia de la Corte Suprema, Rol N 41.815-2016, de 1 de marzo de 2017, c. 41ㅇ․

78 Para Letelier "[...] es un profundo error pensar la multa administrativa en términos retributivos como si a una infracción le correspondiese necesariamente una determinada sanción. La sanción administrativa - como acertadamente sostiene Luciano Parejoes "una técnica más al servicio de la efectividad de las políticas públicas formalizadas en los programas legales a ejecutar por la
} 
otras medidas o simplemente un mero llamado advertencia al infractor para que corrija su comportamiento $^{79}$. Por su parte, elección y, en su caso, la determinación del rango y monto de la sanción siempre deberá estar orientado al fin que busca alcanza la autoridad ${ }^{80}$.

Así, es posible sostener que en la actualidad el legislador no concibe el funcionamiento de los órganos administrativos sin potestades punitivas ${ }^{81}$, puesto que las considera necesarias para la satisfacción de sus objetivos ${ }^{82}$. La sanción es, en efecto, una de las tantas herramientas que tiene la autoridad para cumplir sus fines y lograr la satisfacción del interés general ${ }^{83}$. En otras palabras, la autoridad administrativa como aplicador de sanciones requiere de un marco de acción que le permita adaptar su actividad a la consecución de sus fines ${ }^{84}$.

Así, la entidad de que se trate podría determinar la procedencia de potestades de prima ratio, de manera previa o en reemplazo de la sanción, tales como: la advertencia, un acuerdo autorregulación, una medida provisional, entre otras ${ }^{85}$.

Por ello, el legislador ha atribuido a la Administración potestades discrecionales para el ejercicio de poderes punitivos, de modo que aquella pueda determinar, conforme a las particulares circunstancias del caso concreto, si serán estas u otras las herramientas, las más efectivas para su logro. Por tanto, el establecimiento de dichas potestades en este ámbito no solo es aconsejable, sino que resulta fundamental para un adecuado y oportuno cumplimiento de los fines ${ }^{86}$.

A nivel nacional esta forma de ponderación de las potestades administrativas ya ha sido sostenida por algunos autores, quienes hablan de un cambio de paradigma conforme al cual la sanción sea concebida como un instrumento de carácter administrativo, por tanto, residual en el fin de prevenir y enmendar faltas al ordenamiento jurídico ${ }^{87}$.

\subsection{La imposibilidad de una aplicación mecánica de la ley y la necesidad de un ámbito específico de discrecionalidad}

Por otra parte, la autoridad tampoco se puede transformar en un autómata ejecutor de la ley ${ }^{88}$. La aplicación de sanciones no es un proceso automático en el cual constatada la infracción se asigna de manera mecánica una sanción ${ }^{89}$. Por el contrario, la imposición de sanciones y en general el ejercicio de la potestad punitiva de la Administración, requieren de un análisis reflexivo por parte del órgano respectivo, un ejercicio de adaptación y ajuste a las condiciones específicas del caso concreto $^{90}$.

\footnotetext{
Administración”. O, como también ha sostenido Silva Sánchez, "[...] el Derecho administrativo sancionador es el refuerzo de la ordinaria gestión de la Administración", en LETELIER (2016).

${ }^{79}$ Véase Superintendencia de Educación, Dictamen № 17, de 2015, que establecen los criterios que deberá tener en consideración dicha entidad para iniciar o no un procedimiento sancionatorio.

${ }^{80}$ Véase artículo 39, Ley № 21.000, de 2017.

${ }^{81}$ AGUERREA (2005), p. 51.

${ }^{82}$ CURY (2005), p. 109. Por su parte, Rodríguez señala que el “[...] incremento de la actividad estatal tenía que ir aparejado de la previsión de un cierto número de sanciones que asegurara la efectividad de las nuevas funciones que la Administración había tomado sobre sí", en RODRÍGUEZ (1987), p. 120.

${ }^{83}$ PAREJO (2014), p. 20 y CASINO (1999), p. 341. En Chile véase GUILOFF Y SOTO (2015), p. 101.

${ }^{84}$ LONDOÑO (2014), pp. 160 y 161.

${ }^{85}$ ARANCIBIA (2014), pp. 129-147.

${ }^{86}$ ARÓSTICA (1987), pp. 109-125.

${ }^{87}$ ARANCIBIA (2014), pp. 133-134.

88 LÓPEZ (1947), p. 485.

${ }^{89}$ CORDERO (2014), pp. 185 y ss.

90 Para Vermeule no es posible exigir que la ley contemple todos los detalles, por motivos de prácticos, de conveniencia o de necesidad. Para el autor, el poder de llenar los detalles es un elemento indispensable de lo que significa el poder "ejecutivo", conforme al cual
} 
Cualquiera que sea el sector de que se trate, la forma de comisión de las infracciones, sus efectos y las propias características de los sujetos regulados serán ineludiblemente distintas. A este contexto, se suman los objetivos y fines que debe garantizar el respectivo órgano administrativo. En suma, el ejercicio de la potestad punitiva debe necesariamente ponderar una multiplicidad de factores, los cuales no son posibles de procesar de manera automática, sino que mediante un esquema de equilibrios y contrapesos.

Una adecuada gestión de la actividad administrativa debe estar dirigida a establecer una relación armónica entre potestades regladas y discrecionales, mediante un sistema de contrapesos entre ambas que permita evitar, por una parte, los excesos y la arbitrariedad y, por la otra, la rigurosidad extrema de la ley ${ }^{91}$.

Desde esta perspectiva, la discrecionalidad atribuida en términos abstractos debe ser ajustada por la autoridad al caso concreto mediante la adopción de una decisión singular. Es precisamente la necesidad de adecuar la norma general a las situaciones específicas lo que hace que la potestad discrecional en el ámbito punitivo sea establecida como una herramienta que contribuye a su correcto ejercicio ${ }^{92}$.

La Administración precisa analizar y ponderar las circunstancias específicas del caso, las condiciones del autor, las particularidades de la infracción, la concurrencia de supuestos de exoneración de la responsabilidad, los criterios de atenuación o agravación de las sanciones y los fines que busca alcanzar con su imposición. A partir de la revisión de estos supuestos, la autoridad podrá adoptar una determinada decisión: aplicar una medida represiva, decidir o no la iniciación de un procedimiento sancionador, valorar la autodenuncia formulada por el infractor, establecer la adopción de medidas alternativas, disponer planes de cumplimento e, inclusive, en algunos casos, valorar la suspensión o condonación de la misma.

Por todo ello, el legislador ha considerado pertinente establecer un ámbito específico de discrecionalidad para el ejercicio del poder punitivo, el que si bien puede variar con el tiempo y modificarse los diversos niveles de densidad regulatoria en que fue dispuesta, permanece como una constante en diversos preceptos sancionatorios.

Los órganos administrativos estarán más familiarizados con la dinámica del sector y en mejores condiciones que el legislador para diseñar las directrices con las cuales cumplirán sus cometidos, puesto que manejan y conocen su funcionamiento y objetivos institucionales y se encuentran en mejores condiciones para afrontar, desde una perspectiva global, respuestas a las múltiples situaciones que subyacen en un mundo cada vez más complejo.

En definitiva, el dinamismo de la actividad administrativa en general y, de la función represiva en particular, exige un cierto margen de acción para que la autoridad pueda ejecutar su programación normativa conforme a los fines de interés general que persigue.

\footnotetext{
ejecutar una ley implica inevitablemente darle una especificación adicional, en el curso de su aplicación a problemas y casos reales. En suma, la legislación general nunca puede ir por completo, por así decirlo, a los hechos reales de casos particulares, en VERMEULE (2016), pp. 52-53 [traducción propia].

${ }^{91}$ En este sentido Alejandro Nieto sostiene que "[...] el arbitrio judicial y la discrecionalidad administrativa son el saludable -e inevitablecontrapeso de los rigores de la legalidad y lo que explica que ésta no produzca los desastrosos efectos que de otra suerte resultarían", NIETO (2005), pp. 248 y 249.

${ }^{92}$ En términos generales, para el Tribunal Constitucional, citando a la doctrina comparada, "[...] la razón de la existencia de potestades con elementos discrecionales radica, por una parte, en que en la potestad íntegramente reglada no hay espacio para ningún juicio subjetivo, salvo el de constatación o verificación del supuesto para su ejercicio. Ese diseño puede hacer extremadamente difícil su aplicación. Por la otra, hay un criterio de eficacia. Para lograr ciertos propósitos de modo idóneo, el legislador convoca a la apreciación singular de un órgano determinado", en STC, Rol № 1.341-2009, de 15 de abril de 2010, c. 14.
} 


\subsection{La discrecionalidad y sus contrapesos}

No existen actos administrativos exentos del control judicial desde que los tribunales pueden revisar la plena conformidad a Derecho de cualquier acto de la autoridad ${ }^{93}$. Por tanto, todo acto estatal ha de ser conforme a Derecho en todos los requisitos, circunstancias y exigencias. Además, conforme a lo dispuesto en el artículo $2^{\circ}$ de la Ley № $18.575^{94}$, todos los órganos públicos están sujetos al ordenamiento jurídico consecuencia de lo cual, "Todo abuso o exceso en el ejercicio de sus potestades dará lugar a las acciones y recursos correspondientes".

Por su parte, la discrecionalidad en sí misma no constituye arbitrariedad, sino que es su ejercicio abusivo y al margen de límites el que se encuentra proscrito. Para evitar los excesos a los cuales se puede llegar con este poder, existen una serie de límites para un ejercicio responsable del mismo, encontrándose, además, sometido a diversos mecanismos de control, los cuales permiten y equilibran este poder.

Uno de los primeros límites es aquel establecido por el propio legislador, quien proporciona parámetros para el ejercicio de la potestad ${ }^{95}$. Enseguida, será la propia autoridad, en el ejercicio de la potestad quien establezca criterios, sea con carácter general mediante interpretaciones internas a su normativa ${ }^{96}$ o de carácter particular, en la resolución que recaiga sobre la situación concreta. Finalmente, el acto administrativo sancionador estará sujeto a la revisión judicial, instancia en la cual se controlará si el ejercicio de la potestad administrativa se ajustó a la legalidad, para lo cual tendrán en especial consideración los criterios de motivación empleados por aquella en la integración del supuesto de hecho de la norma.

En definitiva, sostener que la discrecionalidad es necesaria para el logro de los fines encargados a la Administración y, por tanto, un pilar estructural del sistema sancionatorio no implica la ausencia de límites, los cuales serán de suma relevancia para controlar su correcto ejercicio ${ }^{97}$. Además, la admisión de la discrecionalidad en el ejercicio del poder sancionador no altera los derechos, garantías y principios que han sido reconocidos en este ámbito ${ }^{98}$.

En este sentido, la jurisprudencia sostiene la plena legalidad de aquellas disposiciones que atribuyan discrecionalidad a la Administración para imponer una sanción dentro de determinados

\footnotetext{
${ }_{93}^{93}$ SOTO (2012), pp. 607-608.

${ }^{94}$ Cuyo texto refundido, coordinado y sistematizado se encuentra fijado en el DFL N 1-19.653, de 2001, del Ministerio Secretaría General de la Presidencia.

${ }^{95}$ En general, las leyes se limitan a enumerar, en términos amplios, una serie de circunstancias, sin especificar si tienen una trascendencia atenuante o agravante, así como tampoco su ponderación concreta. Esto tiene como consecuencia que una misma circunstancia (el daño causado, la posición en el mercado del infractor, entre otras), varíen dependiendo de las conductancias que concurran en un supuesto dado, en IZQUIERDO (2001), p. 238. Asimismo, algunos criterios se muestran antagónicos o con consecuencias contrapuestas, lo que la doctrina explica en atención a la imposibilidad material de tipificar todas las infracciones con sus circunstancias objetivas y subjetivas, en TORNOS (1975), pp. 607 y ss.

${ }_{96}^{96}$ Por ejemplo, guías, instrucciones, circulares, dictámenes, entre otros.

${ }^{97}$ En un sentido más general, Luis Cordero sostiene que la discrecionalidad es una "[...] cuestión estructural del sistema legal actual, donde no es posible concebir organismos administrativos sin potestades discrecionales, pues a través de su entrega es posible dar cumplimiento a los objetivos de promoción social que buscamos como sociedad. De este modo, lo relevante no es detener la discrecionalidad, sino cuáles son los estándares básicos para poder ser titular de ella y cuáles son los mecanismos de control de su ejercicio", en CORDERO (2015), p. 83.

${ }^{98}$ Sobre este aspecto, la Contraloría General de la República ha indicado que " [...] aun cuando en materia administrativa se admite cierta atenuación de los principios que limitan la potestad del Estado para aplicar sanciones, tolerando mayores grados de discrecionalidad, lo cierto es que de ninguna manera ello se podría traducir en la desaparición de tales principios, puesto que sería del todo ilógico que el infractor administrativo carezca de derechos y garantías que se reconocen al delincuente, o que el juez penal tuviera límites que no se apliquen al órgano administrativo sancionador", en Contraloría General de la República, dictamen № 28.226, 22 de junio de 2007.
} 
límites ${ }^{99}$, pero también, hace referencia a la necesaria suficiencia de estos límites para efectos de evitar abusos o excesos ${ }^{100}$.

\section{Conclusiones}

Si bien el principio de legalidad tiene plena vigencia en el ámbito penal y administrativo, cabe señalar que no recibe el mismo tratamiento. En sede penal la gravedad de las medidas punitivas y su fuerte incidencia en la esfera de las personas, exigen de mayores garantías en la configuración de los ilícitos, en la determinación de las penas y en el proceso judicial. Por su parte, en el ámbito administrativo se admite un mayor margen de discrecionalidad, atendiendo a sus fines y medios, aunque sujeto a una serie de límites y controles propios del orden constitucional, que lo alejan del régimen de policía propio del Antiguo Régimen.

La atribución de potestades discrecionales en el ejercicio de los poderes sancionadores de la Administración es una determinación deliberada y consciente del legislador en el marco del orden constitucional. Toda actuación administrativa debe estar precedida por una norma habilitante que permita su ejercicio, lo cual, en el ámbito administrativo sancionador, se traduce en un cúmulo de elementos reglados y discrecionales que se entregan a la autoridad para la consecución de los fines públicos y cuya densidad regulatoria varía, dependiendo del sistema sancionatorio específico de que se trate.

En este sentido, la existencia de discrecionalidad en el ejercicio de poderes punitivos, permite a la Administración orientar su actividad represiva en orden a alcanzar los fines públicos que se le han encomendado, considerando las circunstancias específicas del caso, incluyendo su adecuación a ciertas opciones de política pública $(v$. gr. buen uso de los recursos públicos, eficiencia y eficacia en la gestión, generación de un efecto disuasivo, establecimiento de ámbitos de tolerancia, etc.).

Si bien el legislador está facultado para regular en todos sus detalles el ejercicio de la potestad sancionadora de la Administración, aquello no se manifiesta en toda su intensidad, debido a la dificultad e inconveniencia de determinar ex ante el qué (supuesto de hecho concreto); el cuándo (oportunidad); el cuánto (tipo y, en su caso, monto específico de la sanción) y el para qué (en orden a la finalidad que se pretende alcanzar). Así, la multiplicidad de supuestos que pueden dar lugar al ejercicio de la potestad represiva exige un cierto margen de acción, para que la autoridad pueda ejecutar su programación normativa y los fines de interés general que persigue con ella ( $v$. gr. protección del medio ambiente, estabilidad de los mercados financieros, calidad de la educación,

\footnotetext{
99 Véase sentencias de la Corte Suprema, Rol № 9.136-2011, de 9 de diciembre de 2013, c. 17ㅇ; Rol № 17.736-2016, 13 de diciembre de 2016, c. 170; Rol № 68.722-2016, 8 de febrero de 2017, c. 6 y Rol № 68.723-2016, de 14 de marzo de 2017, c. 9‥ En la especie, dichos considerados hacen referencia a la discrecionalidad que existe en aquellos preceptos en los cuales se ha establecido un "marco de sanción", precisando que la aplicación de la misma corresponde tanto al órgano administrativo que la impone como al órgano jurisdiccional revisor de lo actuado. Asimismo, a nivel comparado, véase las STCE, Rol № 175/2012, de 15 de octubre de 2012 (fj. 3) y Rol № 145/2013, de 11 de julio de 2013 (fj. 8).

${ }^{100}$ En este sentido, el Tribunal Constitucional chileno ha indicado en su STC Rol N².922-2015, de 29 de septiembre de 2016, “[...] la aplicación del inciso primero del artículo 29 del DL N³.538, de 1980, al caso concreto, produce efectos contrarios a la Constitución [...], específicamente, al principio de proporcionalidad, desde que su materialización fáctica no se sustenta sobre la base de criterios de razonabilidad (objetivos y ponderados) que permitan determinar por qué se ha impuesto una determinada sanción, e incluso, por qué un porcentaje específico y no otro". c. 49․ Por su parte, en la sentencia de la Corte Suprema, Rol № 68.723-2016, de 14 de marzo de 2017, se sostuvo: "Décimo: Que, si bien es cierto que la Ley 18.410 proporciona un rango que puede recorrerse al momento de regular el monto específico de la multa en cuestión, lo que da cuenta de la entrega de cierto ámbito de discrecionalidad al órgano administrativo, dicha facultad no puede derivar en la fijación de una cuantía arbitraria, sin explicitación de los motivos que se tuvieron en cuenta para la valoración de la sanción pecuniaria, de manera de permitir al administrado la realización de un examen de proporcionalidad entre la infracción imputada y el castigo finalmente aplicado".
} 
salubridad pública, la hacienda pública, entre otros). Por tal motivo, la discrecionalidad corresponde a una atribución necesaria para el ejercicio de la potestad sancionadora de la Administración, a través de la cual se busca resguardar bienes jurídicos supraindividuales.

Finalmente, el concepto de discrecionalidad que en esta investigación se sigue es amplio, comprensivo de todos los supuestos que atribuyen un margen de decisión a los órganos de la Administración en el marco del procedimiento administrativo sancionador. Por tanto, no solo hay discrecionalidad cuando el legislador la configura directamente o mediante fórmulas que habilitan su ejercicio, sino que también hay discrecionalidad en los casos en que el legislador utiliza conceptos jurídicos indeterminados, imponiendo a la autoridad el deber de precisar, dentro de un margen de apreciación, la zona de incertidumbre o vaguedad de los mismos, por cuanto en dicho ámbito su aplicación exige una decisión del órgano. Así, existe discrecionalidad en materia administrativa sancionadora cada vez que la ley configura una norma jurídico-administrativa mediante supuestos de hecho imperfectos, inacabados, indeterminados o inexistentes, habilitando a la autoridad administrativa para completar o integrar, al momento de su aplicación, aquel supuesto a través del establecimiento de criterios. De esta manera, la discrecionalidad entra en acción precisamente cuando las exigencias de legalidad se han agotado.

\section{BIBLIOGRAFÍA CITADA}

AgUeRreA, PEDRO (2005): "El estatuto constitucional de las penas. Su aplicación a las sanciones administrativas conforme a los antecedentes de la Comisión de Estudio de la Nueva Constitución", en: Soto Kloss, Eduardo (Coord.), Sanciones Administrativas y Derechos fundamentales: regulación y nuevo intervencionismo (Santiago, Universidad Santo Tomás), pp. 51-62.

ARANCIBIA, JAIME (2014): "El principio de necesidad de la sanción administrativa como potestad de ultima ratio", en: Arancibia, Jaime y Alarcón, Pablo (Coords.), Sanciones Administrativas (Santiago, Thomson Reuters - La Ley), pp. 129-147.

ARÓSTICA, IVÁN (1987): "El Derecho Administrativo Sancionador y la proporcionalidad de los actos administrativos (un asunto de justicia distributiva)", en: Revista de Derecho y Jurisprudencia y Gaceta de los Tribunales (Tomo 84, № 3), pp. 109-125.

(1991): “Un lustro de sanciones administrativas (1988-1992)", en: Revista de Derecho Público (№ 50), pp. 13-37.

(2016): "Sanciones y restricciones administrativas", en: Revista de Derecho Público Iberoamericano ( $\mathrm{N}^{\circ}$ 9), pp. 13-37.

BACIGALUPO, MARIANO (1997): La discrecionalidad administrativa (estructura normativa, control judicial y límites constitucionales de la atribución) (Madrid, Marcial Pons).

BAÑO LEÓN, JOSÉ MARÍA (2015): "La discrecionalidad administrativa en las sanciones del Derecho de la Competencia", en: Guillén Caramés, Javier (Dir.), Estudios sobre la potestad sancionadora en el Derecho de la Competencia (Madrid, Thomson Reuters-Civitas, Cizur Menor), pp. 467-486. 
BERMÚDEZ, JORGE (2012): “Discrecionalidad y conceptos jurídicos indeterminados en la actuación de la Administración Pública”, en: Revista de Derecho Administrativo (Nº 7), pp. 3-26.

CASINO, MIGUEL (1999): "El Derecho sancionador y la responsabilidad patrimonial de la Administración”, en: Documentación Administrativa ( $\left.N^{\circ} 254-255\right)$, pp. 319-336.

(2015): "La potestad sancionadora de la administración y vuelta a la casilla de salida", en: Documentación Administrativa. Nueva Época (№ 2).

CASSAGNE, JUAN CARLOS (2016): El principio de legalidad y el control judicial de la discrecionalidad administrativa, 2a edición (Buenos Aires/Montevideo, B de F).

CEA EGAÑA, JOSÉ LUIS (1984): “Hermenéutica constitucional, soberanía legal y discrecionalidad administrativa”, en: Revista Chilena de Derecho (Vol. 11), pp. 7-16.

CORDERO, EDUARDO (2014): Derecho Administrativo Sancionador. Bases y principios en el Derecho chileno (Santiago, LegalPublishing - Thomson Reuters - La Ley).

CORDERO, LUIS (2015): Lecciones de Derecho Administrativo (Santiago, LegalPublishing - Thomson Reuters - La Ley).

CURY, ENRIQUE (2005): Derecho Penal, Parte General, 7ạ edición (Santiago, Editorial Universidad Católica de Chile).

DESDENTADO, EVA (2010): “Discrecionalidad administrativa en la imposición de sanciones", en: Lozano Cutanda, Blanca (Dir.), Diccionario de sanciones administrativas (Madrid, lustel).

DOMENECH, GABRIEL (2019): “El juego del legislador, la administración y el juez”, en: Tratado de Derecho Administrativo (en prensa).

FERNÁNDEZ, TOMÁS RAMÓN (1991): Arbitrariedad y Discrecionalidad (Madrid, Civitas).

(2016): Arbitrario, arbitraire, arbitrary. Pasado y presente de un adjetivo imprescindible en el discurso jurídico (Madrid, lustel).

FERRADA, JUAN CARLOS (2014): "La articulación de las potestades administrativas y jurisdiccionales en la aplicación de sanciones administrativas en el Derecho chileno: poderes distintos, pero complementarios", en: Arancibia, Jaime y Alarcón, Pablo (Coords.), Sanciones Administrativas (Santiago, Thomson Reuters - La Ley), pp. 239-261.

GARCÍA DE ENTERRÍA, EDUARDO Y FERNÁNDEZ, TOMÁS RAMÓN (2011): Curso de Derecho Administrativo, 12ạ edición (Madrid Civitas - Thomson Reuters), tomo II.

GORDILLO, AGUSTín (1974): Tratado de Derecho Administrativo (Buenos Aires, Ediciones Macchi), tomo I. 
GÓMEZ, ROSA FERNANDA (2019): “Antecedentes históricos de la potestad sancionadora de la administración en Chile. Su origen en la actividad de policía", en: Revista Derecho del Estado (Colombia) (№ 44), pp. 361-384.

GUILOFF, MATÍAS Y SOTO, PABLO (2015): "Sanciones administrativas, discrecionalidad y revisión judicial: una mirada desde la regulación responsiva", en: Ferrada, Juan Carlos; Bermúdez, Jorge y Pinilla, Francisco (Coords.), La nueva justicia ambiental (Santiago, Thomson Reuters-La Ley), pp. 101-124.

HUEPE, FABIÁN (2014): "El problema de la discrecionalidad en la potestad sancionadora de la Administración. Su control a través del principio de razonabilidad", en: Arancibia, Jaime y Alarcón, Pablo (Coords.), Sanciones Administrativas (Santiago, Thomson Reuters - La Ley), pp. 168-186.

HUERGO, ALEJANDRO (1995): "La desigualdad en la aplicación de potestades administrativas de gravamen: remedios jurídicos”, en: Revista de Administración Pública (№ 137), pp. 189-238.

(2007): Las sanciones administrativas (Madrid, lustel).

IZQUIERDO, MANUEL (2001): "La determinación de la sanción administrativa, en: Justicia administrativa", en: Revista de Derecho Administrativo (ejemplar dedicado a: Infracciones, sanciones y procedimiento administrativo sancionador) (Número Extraordinario 1), pp. 207-258.

KOCH, HANS-JOACHIM (1979): Unbestimmte Rechtsbegriffe und Ermessensermachtigungen im Verwaltungsrecht (Francfort, Metzner).

KUNH, THOMAS (2015): La estructura de las revoluciones científicas, 20a edición (Traducc. Carlos Solís, Fondo de Cultura Económica, México D.F.).

LETELIER, RAÚl (2016): "Un paso adelante de la Corte Suprema, dos pasos atrás del Tribunal Constitucional: garantías penales y sanciones administrativas", en: El Mercurio Legal. Disponible en: https://www.elmercurio.com/legal/noticias/opinion/2016/12/02/un-paso-adelante-de-la-cortesuprema-dos-pasos-atras-del-tribunal-constitucional-garantias-penales-y-sancionesadministrativas.aspx [visitado el 10 de diciembre de 2019].

LONDOÑO, FERNANDO (2014): "Tipicidad y legalidad en el Derecho administrativo-sancionatorio", en: Revista Derecho (Valdivia) (Vol. 27, № 2), pp. 147-167.

LÓPEZ RODÓ, LAUREANO (1947): “La discrecionalidad de la Administración en el Derecho español”, en: Revista de Estudios de la Vida Local (№ 34), pp. 485-503.

LOZANO, BLANCA (2003): "El principio de oficialidad de la acción sancionadora administrativa", en: Revista de Administración Pública (№ 161), pp. 83-121.

MECCARELLI, MASSIMO (1998): Artitrium. Un aspetto sistematico degli ordinamenti giuridici in età di diritti comune (Milan, Dott A. Giuffreè Editore). 
MUÑOZ MACHADO, SANTIAGO (2017): Diccionario Panhispánico del español jurídico (Madrid, Real Academia Española), tomo I.

NIETO, ALEJANDRO (2000): El arbitrio judicial (Barcelona, Ariel).

(2005): Derecho Administrativo Sancionador, 4ạ edición (Madrid, Tecnos).

PAREJO ALFONSO, LUCIANO (1993): Administrar y juzgar: dos funciones constitucionales distintas y complementarias. Un estudio del alcance y la intensidad del control judicial a la luz de la discrecionalidad administrativa (Madrid, Tecnos).

(2014): "Algunas reflexiones sobre la necesidad de la depuración del status de la sanción administrativa", en: Revista General de Derecho Administrativo (№ 36), pp. 1-26.

QUEZADA, FLAVIO (2017): Procedimiento administrativo sancionador en la Ley $N^{\circ} 19.880$ (Santiago, Librotecnia).

ReBollo, MANUel (2015): “Control judicial del no ejercicio de la potestad sancionadora”, en: Guillén, Javier y Cuerdo, Miguel (Coords.), Estudios sobre la potestad sancionadora en el Derecho de la Competencia (Madrid, Thomson Reuters-Civitas, Cizur Menor), pp. 407-466.

RODRÍGUEZ COLLAO, LUIS (1987): "Bases para distinguir entre infracciones criminales y administrativas", en: Revista de Derecho (Valparaíso) (Vol. 11), pp. 117-163.

RODRÍGUEZ DE SANTIAGO, JOSÉ MARÍA (2016): Metodología del Derecho Administrativo. Reglas de racionalidad para la adopción y el control de la decisión administrativa (Madrid, Marcial Pons).

SÁNCHEZ MORÓN, MIGUEL (1995): Discrecionalidad administrativa y control judicial, reimp. (Madrid, Tecnos).

SANTAMARÍA PASTOR, JUAN ALFONSO Y PAREJO ALFONSO, LUCIANO (1992): Derecho Administrativo. La jurisprudencia del Tribunal Supremo, reimp. (Madrid, Editorial Centro de Estudios Ramón Areces S.A.).

SOTO DELGADO, PABLO (2016): “Determinación de sanciones administrativas: disuasión óptima y confinamiento de la discrecionalidad del regulador ambiental", en: Couso, Javier (Ed.), Anuario de Derecho Público (Santiago, Universidad Diego Portales), pp. 374-407.

SOTO KLOSS, EDUARDO (2009): Derecho Administrativo. Temas Fundamentales (Santiago, AbeledoPerrot - Legal Publishing).

Publishing).

(2012): Derecho Administrativo. Temas Fundamentales, 3ạ edición (Santiago, Legal 
(2014): Otra vez sobre la potestad sancionadora de la Administración, en: Arancibia Mattar, Jaime y Alarcón Jaña, Pablo (Coords.), Sanciones Administrativas (Santiago, Thomson Reuters - La Ley, 2014), pp. 39-52.

SUBRA DE BIEUSSESS, PIERRE (1994): "La potestad discrecional", en: Revista Documentación Administrativa (№ 239), pp. 31-69.

TORNOS MAS, JOAQUÍN (1975): "Infracción y sanción administrativa: el tema de su proporcionalidad en la jurisprudencia contencioso-administrativa”, en: Revista Española de Derecho Administrativo (№ 7), pp. 607-624.

VAN WEEZEL, ALEX (2017): "Sobre la necesidad de un cambio de paradigma en el derecho sancionatorio administrativo", en: Política Criminal (Vol. 12, № 24, Art. 9), pp. 1015-1016.

VERMEULE, ADRIAN (2016): Law's Abnegation. From Law's Empire to the Administrative State (Cambridge, Harvard University Press).

\section{JURISPRUDENCIA CITADA}

\section{TRIBUNALES ORDINARIOS}

ECCOL LTDA. CON SEREMI DE SALUD (2010): Corte Suprema 25 de abril de 2012 (recurso de casación en el fondo).

SOLARI FALABEL, MARÍA LUISA, ZAROUR ATANACIO MARCEL CON SVS (2011): Corte Suprema 9 de diciembre de 2013 (casación en la forma y en el fondo).

ENDESA CON SMA (2016): Corte Suprema 13 de diciembre de 2016 (casación en la forma y en el fondo). Empresa Eléctrica Aysén S.A. con SEC (2017): Corte Suprema 8 de febrero de 2017 (apelación reclamación).

PAMPA CAMARONES S.A CON SMA (2017): Corte Suprema 1 de marzo de 2017 (casación en la forma y fondo).

GASCO GLP S.A. CON SEC (2017): Corte Suprema 14 de marzo de 2017 (apelación reclamación).

\section{TRIBUNAL CONSTITUCIONAL CHILENO}

CONTROL DE CONSTITUCIONALIDAD RESPECTO DEL PROYECTO DE LEY SOBRE TRANSPARENCIA, LÍMITE Y CONTROL DEL GASTO ELECTORAL (2003): Tribunal Constitucional 17 de junio de 2003 (control de constitucionalidad).

CONTROL DE CONSTITUCIONALIDAD RESPECTO DEL PROYECTO DE LEY QUE CREA LA UNIDAD DE ANÁLISIS FINANCIERO Y MODIFICA EL CÓDIGO PENAL EN MATERIA DE LAVADO Y BLANQUEO DE ACTIVOS (2003): Tribunal Constitucional 28 de octubre de 2003 (control de constitucionalidad). 
REQUERIMIENTO DE INAPLICABILIDAD POR INCONSTITUCIONALIDAD DE IBEROAMERICANA DE ENERGÍA IBENER S.A., RESPECTO DEL ARTÍCULO $3^{\circ} \mathrm{N}^{\circ} 17$, INCISO $4^{\circ} \mathrm{Y} \mathrm{N}^{\circ} 23$, INCISO $1^{\circ}, 15,16 \mathrm{~N}^{\circ} 2$ Y 16 A DE LA LEY 18.410, EN LA CAUSA ROL Nº 5.816-2004 DE LA CORTE DE APELACIONES DE SANTIAGO (2006): Tribunal Constitucional de 27 de julio de 2006 (requerimiento de inaplicabilidad por inconstitucionalidad).

REQUERIMIENTO DE INAPLICABILIDAD POR INCONSTITUCIONALIDAD DE RAÚL GONZÁLEZ GUZMÁN, RESPECTO DEL ARTÍCULO 248 DEL CÓDIGO PROCESAL PENAL, EN CAUSA RUC 0810018505-K Y RIT 982-2008, DEL JUZGADO DE LETRAS DE PUCÓN (2010): Tribunal Constitucional de 15 de abril de 2010 (requerimiento de inaplicabilidad por inconstitucionalidad).

REQUERIMIENTO DE INAPLICABILIDAD POR INCONSTITUCIONALIDAD DE MARÍA ANGÉLICA SÁNCHEZ VOGEL Y OTROS, RESPECTO DEL ARTÍCULO 169 DEL CÓDIGO SANITARIO, EN RECURSO DE AMPARO ROL № 3073-2009 DE LA CORTE DE APELACIONES DE SANTIAGO (2010): Tribunal Constitucional de 21 de octubre de 2010 (requerimiento de inaplicabilidad por inconstitucionalidad).

REQUERIMIENTO DE INCONSTITUCIONALIDAD PRESENTADO POR UN GRUPO DE DIPUTADOS QUE REPRESENTAN LA CUARTA PARTE DE LOS MIEMBROS EN EJERCICIO RESPECTO DE LOS PRECEPTOS QUE INDICAN DEL PROYECTO DE LEY QUE PERMITE LA INTRODUCCIÓN DE LA TELEVISIÓN DIGITAL TERRESTRE, CONTENIDO EN EL BOLETÍN № 6190-19 (2013): Tribunal Constitucional 18 de noviembre de 2013 (requerimiento de inaplicabilidad por inconstitucionalidad).

REQUERIMIENTO DE INAPLICABILIDAD POR INCONSTITUCIONALIDAD PRESENTADO POR ROBERTO GUZMÁN LYON RESPECTO DEL ARTÍCULO 29 DEL DL N³.538, DE 1980, QUE CREA LA SUPERINTENDENCIA DE VALORES Y SEGUROS, EN LOS AUTOS SOBRE JUICIO SUMARIO DE RECLAMACIÓN DE MULTA, CARATULADOS “GUZMÁN LYON, ROBERTO CON SUPERINTENDENCIA DE VALORES Y SEGUROS", DE QUE CONOCE EL $16^{\circ}$ JUZGADO CIVIL DE SANTIAGO, BAJO EL ROL C21.305-2014 (2016): Tribunal Constitucional 29 de septiembre de 2016 (Requerimiento de inaplicabilidad por inconstitucionalidad).

REQUERIMIENTO DE INAPLICABILIDAD POR INCONSTITUCIONALIDAD PRESENTADO POR MANUEL BULNES MUZARD Y FELIPE ERRÁZURIZ AMENÁBAR RESPECTO DEL INCISO PRIMERO DEL ARTÍCULO 29 DEL D.L. N 3.538, DE 1980, LEY ORGÁNICA DE LA SUPERINTENDENCIA DE VALORES Y SEGUROS, EN LOS AUTOS SOBRE JUICIO SUMARIO DE RECLAMACIÓN DE MULTA, CARATULADOS “BULNES Y OTRO CON SUPERINTENDENCIA DE VALORES Y SEGUROS”, DE QUE CONOCE EL $23^{\circ}$ JUZGADO CIVIL DE SANTIAGO, BAJO EL ROL C-21.498-2014 (2017): Tribunal Constitucional 14 de noviembre de 2017 (requerimiento de inaplicabilidad por inconstitucionalidad).

CONTROL DE CONSTITUCIONALIDAD DEL PROYECTO DE LEY QUE MODIFICA LEY N 19.496, SOBRE PROTECCIÓN DE LOS DERECHOS DE LOS CONSUMIDORES, CORRESPONDIENTE AL BOLETÍN N 9369-03 (2018): Tribunal Constitucional 18 de enero de 2018 (control de constitucionalidad).

REQUERIMIENTO DE INAPLICABILIDAD POR INCONSTITUCIONALIDAD PRESENTADO POR ALBERTO LE BLANC MATTHAEI RESPECTO DEL INCISO PRIMERO DEL ARTÍCULO 29 DEL D.L. №3.538, DE 1980, LEY ORGÁNICA DE LA SUPERINTENDENCIA DE VALORES Y SEGUROS, EN EL PROCESO SOBRE RECLAMACIÓN DE MULTA, ROL C-20.605-2014, DEL 20 JUZGADO CIVIL DE SANTIAGO, CARATULADO "LE BLANC MATTHAEI, ALBERTO CON SUPERINTENDENCIA DE VALORES Y SEGUROS", DE QUE CONOCE ACTUALMENTE LA CORTE DE APELACIONES DE SANTIAGO, POR RECURSO DE APELACIÓN, BAJO EL ROL N²8042017 (2018): Tribunal Constitucional 7 de mayo de 2018 (requerimiento de inaplicabilidad por inconstitucionalidad).

REQUERIMIENTO DE INAPLICABILIDAD POR INCONSTITUCIONALIDAD PRESENTADO POR LARRAÍN VIAL S.A. RESPECTO DEL INCISO PRIMERO DEL ARTÍCULO 29 DEL D.L. N 3.538, DE 1980, LEY ORGÁNICA DE LA SUPERINTENDENCIA DE VALORES Y SEGUROS, EN LOS AUTOS SOBRE JUICIO SUMARIO DE RECLAMACIÓN DE MULTA, CARATULADOS “LARRAÍN VIAL S.A. 
CORREDORES DE BOLSA CON SUPERINTENDENCIA DE VALORES Y SEGUROS", ROL C-21.500-2014, DEL 29 JUZGADO CIVIL DE SANTIAGO, DE QUE CONOCE ACTUALMENTE LA CORTE DE APELACIONES DE SANTIAGO, POR RECURSO DE APELACIÓN, BAJO EL ROL 561-2016, ACUMULADA AL ROL DE INGRESO CORTE N 13.070-2015 (2018): Tribunal Constitucional 7 de mayo de 2018 (requerimiento de inaplicabilidad por inconstitucionalidad).

REQUERIMIENTO DE INAPLICABILIDAD POR INCONSTITUCIONALIDAD PRESENTADO POR LEONIDAS VIAL ECHEVERRÍA, RESPECTO DEL INCISO PRIMERO DEL ARTÍCULO 29 DEL D.L. №3.538, DE 1980, LEY ORGÁNICA DE LA SUPERINTENDENCIA DE VALORES Y SEGUROS, EN LOS AUTOS SOBRE JUICIO SUMARIO DE RECLAMACIÓN DE MULTA, CARATULADOS “LARRAÍN VIAL S.A. CORREDORES DE BOLSA CON SUPERINTENDENCIA DE VALORES Y SEGUROS", ROL C-21.500-2014, DEL 29 JUZGADO CIVIL DE SANTIAGO, DE QUE CONOCE ACTUALMENTE LA CORTE DE APELACIONES DE SANTIAGO, POR RECURSO DE APELACIÓN, BAJO EL ROL 561-2016, ACUMULADA AL ROL DE INGRESO CORTE N 13.070-2015 (2017): Tribunal Constitucional 7 de mayo de 2018 (requerimiento de inaplicabilidad por inconstitucionalidad).

REQUERIMIENTO DE INAPLICABILIDAD POR INCONSTITUCIONALIDAD PRESENTADO POR JULIO PONCE LEROU RESPECTO DEL INCISO PRIMERO DEL ARTÍCULO 29 DEL D.L. N³.538, DE 1980, LEY ORGÁNICA DE LA SUPERINTENDENCIA DE VALORES Y SEGUROS, EN LOS AUTOS SOBRE JUICIO SUMARIO DE RECLAMACIÓN DE MULTA, DEL $18^{\circ}$ JUZGADO CIVIL DE SANTIAGO, CARATULADOS "PONCE CON SUPERINTENDENCIA DE VALORES Y SEGUROS", DE QUE CONOCE ACTUALMENTE LA CORTE DE APELACIONES DE SANTIAGO, POR RECURSO DE APELACIÓN, BAJO EL ROL N 7250-2016 (2018): Tribunal Constitucional 24 de mayo de 2018 (requerimiento de inaplicabilidad por inconstitucionalidad).

REQUERIMIENTO DE INAPLICABILIDAD POR INCONSTITUCIONALIDAD PRESENTADO POR LA CISTERNA EXPRESS LTDA. RESPECTO DEL ARTÍCULO 19 DE LA LEY N 18.410, EN LOS AUTOS SOBRE RECURSO DE RECLAMACIÓN CARATULADOS "SOCIEDAD COMBUSTIBLES LA CISTERNA EXPRESS LIMITADA CON SUPERINTENDENCIA DE ELECTRICIDAD Y COMBUSTIBLES DE LA ARAUCANÍA", DE QUE CONOCE LA CORTE DE APELACIONES DE TEMUCO, BAJO EL ROL N $492-2017$ (2019): Tribunal Constitucional 5 de marzo de 2019 (requerimiento de inaplicabilidad por inconstitucionalidad).

\section{TRIBUNAL CONSTITUCIONAL ESPAÑOL}

STCE, ROL N²07/1990, de 17 de diciembre de 1990, recurso de amparo.

STCE, ROL N 14/1998, de 21 enero de 1998, recurso de inconstitucionalidad.

STCE, ROL № 175/2012, de 15 de octubre de 2012, recurso de amparo.

STCE, ROL N 145/2013, de 11 de julio de 2013, cuestión de constitucionalidad.

\section{JURISPRUDENCIA ADMINISTRATIVA}

CONTRALORÍA GENERAL DE LA REPÚBLICA, dictamen № 28.226, 22 de junio de 2007.

CONTRALORÍA GENERAL DE LA REPÚBLICA, dictamen № 71.670, de 14 de septiembre de 2014.

\section{NORMAS JURÍDICAS CITADAS}

DL № 3.538, que crea la Comisión para el Mercado Financiero. Diario Oficial, 23 de diciembre de 1980. 
LEY № 18.410, que crea la Superintendencia de Electricidad y Combustibles. Diario Oficial, 22 de mayo de 1985.

LEY № 18.755, establece normas sobre el Servicio Agrícola y Ganadero, deroga la Ley № 16.640 y otras disposiciones. Diario Oficial, 7 de enero de 1989.

DFL No 1-19.653, del Ministerio Secretaría General de la Presidencia, que fija texto refundido, coordinado y sistematizado de la Ley № 18.575, Orgánica Constitucional de Bases Generales de la Administración del Estado. Diario Oficial, 1 de noviembre de 2001.

LEY № 20.417, que crea el Ministerio, el Servicio de Evaluación Ambiental y la Superintendencia del Medio Ambiente. Diario Oficial, 26 de enero de 2010.

LEY № 21.000, que crea la Comisión para el Mercado Financiero. Diario Oficial, 23 de febrero de 2017.

LEY № 21.020, sobre tenencia responsable de mascotas y animales de compañía. Diario Oficial, 2 de agosto de 2017.

LEY № 21.064, que introduce modificaciones al marco normativo que rige las aguas en materia de fiscalización y sanciones. Diario Oficial, 27 de enero de 2018. 